\title{
Two- and three-dimensional bearing capacity of footings in sand
}

\author{
A. V. LYAMIN*, R. SALGADO $\uparrow$, S. W. SLOAN* and M. PREZZI†
}

Bearing capacity calculations are an important part of the design of foundations. Many of the terms in the bearing capacity equation, as it is used today in practice, are empirical. Shape factors could not be derived in the past because three-dimensional bearing capacity computations could not be performed with any degree of accuracy. Likewise, depth factors could not be determined because rigorous analyses of foundations embedded in the ground were not possible. In this paper, the bearing capacity of strip, square, circular and rectangular foundations in sand are determined for frictional soils following an associated flow rule using finite-element limit analysis. The results of the analyses are used to propose values of the shape and depth factors for calculation of the bearing capacity of foundations in sands using the traditional bearing capacity equation. The traditional bearing capacity equation is based on the assumption that effects of shape and depth can be considered separately for soil self-weight and surcharge (embedment) terms. This assumption is not realistic, so a different form of the bearing capacity equation is also proposed that does not rely on it.

KEYWORDS: bearing capacity; footings/foundations; limit analysis; sand
Les calculs de force portante sont un élément important de l'étude des fondations. Un grand nombre des termes utilisés dans l'équation de force portante, tels qu'ils sont utilisés à l'heure actuelle, sont empiriques. Autrefois, il n'était pas possible de dériver des coefficients de forme car on ne pouvait effectuer des calculs tridimensionnels de force portante avec la précision nécessaire. De même, il n'était pas possible de déterminer des facteurs de profondeur, car l'exécution d'analyses rigoureuses de fondations encastrées dans le sol n'était pas possible. Dans la présente communication, on détermine la force portante de fondations linéaires, carrées, circulaires et rectangulaires dans le sable pour des sols à frottement, à la suite d'une règle d'écoulement, au moyen d'une analyse des limites aux éléments finis. On utilise les résultats de ces analyses pour proposer des valeurs de coefficients de forme et de profondeur pour le calcul de la force portante des fondations dans le sable, en utilisant l'équation de force portante traditionnelle. L'équation de force portante traditionnelle est fondée sur une hypothèse d'après laquelle les effets de la forme et de la profondeur peuvent être examinés séparément pour la charge propre et la surcharge (enfouissement). Cette hypothèse n'étant pas réaliste, nous proposons également une forme d'équation de force portante diverse non basée sur cette hypothèse.

\section{INTRODUCTION}

The bearing capacity equation (Terzaghi, 1943; Meyerhof, 1951, 1963; Brinch Hansen, 1970) is one tool that geotechnical engineers employ routinely. It is used to estimate the limit unit load $q_{\mathrm{bL}}$ (referred to also as the limit unit bearing capacity or limit unit base resistance) that will cause a footing to undergo classical bearing capacity failure. For a footing with a level base embedded in a level sand deposit acted upon by a vertical load, the bearing capacity equation has the form

$$
q_{\mathrm{bL}}=\left(s_{\mathrm{q}} d_{\mathrm{q}}\right) q_{0} N_{\mathrm{q}}+0 \cdot 5\left(s_{\gamma} d_{\gamma}\right) \gamma B N_{\gamma}
$$

where $N_{\mathrm{q}}$ and $N_{\gamma}$ are bearing capacity factors; $s_{\mathrm{q}}$ and $s_{\gamma}$ are shape factors; $d_{\mathrm{q}}$ and $d_{\gamma}$ are depth factors; $q_{0}$ is the surcharge at the footing base level; and $\gamma$ is the soil unit weight below the footing base level. The limit unit load is a load divided by the plan area of the footing, and has units of stress. In the case of a uniform soil profile, with the unit weight above the level of the footing base also equal to $\gamma$, we have $q_{0}=\gamma D$. The unit weight $\gamma$, the footing width $B$ and the surcharge $q_{0}$ can be considered as given. The other terms of equation (1) must be calculated or estimated by some means.

Manuscript received 6 June 2005; revised manuscript accepted 26 June 2007.

Discussion on this paper closes on 1 April 2008, for further details see p. ii.

* Centre for Geotechnical and Materials Modelling, University of Newcastle, New South Wales, Australia.

$\dagger$ School of Civil Engineering, Purdue University, West Lafayette, IN, USA.
Most theoretical work done in connection with the bearing capacity problem has been for soils following an associated flow rule. This also applies to the present paper. Until recently, the only term of equation (1) that was known rigorously was $N_{\mathrm{q}}$ (for zero self-weight), which follows directly from consideration of the bearing capacity of a strip footing on the surface of a weightless, frictional soil (Reissner, 1924; see also Bolton, 1979),

$$
q_{\mathrm{bL}}=q_{0} N_{\mathrm{q}}
$$

where $N_{\mathrm{q}}$ is calculated from

$$
N_{\mathrm{q}}=\frac{1+\sin \phi}{1-\sin \phi} \mathrm{e}^{\pi \tan \phi}
$$

Considering a strip footing on the surface of frictional soil with non-zero unit weight $\gamma$ and $q_{0}=0$, the unit bearing capacity is calculated from

$$
q_{\mathrm{bL}}=0.5 \gamma B N_{\gamma}
$$

There are two equations for the $N_{\gamma}$ in equation (4) that have been widely referenced in the literature,

$$
N_{\gamma}=1 \cdot 5\left(N_{\mathrm{q}}-1\right) \tan \phi
$$

by Brinch Hansen (1970) and

$$
N_{\gamma}=2\left(N_{\mathrm{q}}+1\right) \tan \phi
$$

by Caquot \& Kerisel (1953).

Although equation (5) was developed at a time when computations were subject to greater uncertainties, it is close to producing exact values for a frictional soil following an associated flow rule for relatively low friction angle values. It tracks well the results of slip-line analyses done by 
Hansen \& Christensen (1969), Booker (1969) and Davis \& Booker (1971) for a strip footing on the surface of a frictional soil with self-weight up to a $\phi$ value of roughly $40^{\circ}$. Martin (2005) found values of $N_{\gamma}$ based on the slip-line method that are very accurate. Salgado (2008) proposed a simple equation, in a form similar to equation (5), that fits those values quite well:

$$
N_{\gamma}=\left(N_{\mathrm{q}}-1\right) \tan (1 \cdot 32 \phi)
$$

Equation (1) results from the superposition of the bearing capacity due to the surcharge $q_{0}$ with that due to the selfweight of the frictional soil. While the values of $N_{\mathrm{q}}$ and $N_{\gamma}$ satisfy a standard of rigour when used independently for the two problems for which they were developed, it is not theoretically correct to superpose the surcharge and selfweight effects (in fact, the surcharge is due to the selfweight of the soil located above the footing base). Still, while not theoretically correct, the superposition of the two solutions as in equation (1) has been used in practice for decades. Smith (2005) has recently shown that the error introduced by superposition may be as high as $25 \%$.

In addition to superposing the effects of surcharge and self-weight, each of the two terms on the right side of equation (1) contains shape and depth factors. The shape factors are used to model the problem of the bearing capacity of a footing with finite dimensions in both horizontal directions, and the depth factors are used to model the problem in which the surcharge is in reality a soil overburden due to embedment of the footing in the soil. The equations for these factors have been determined empirically, based on relatively crude models (Meyerhof, 1963; Brinch Hansen, 1970; Vesic, 1973). Tables 1 and 2 contain the expressions more commonly used for the shape and depth factors, due to Meyerhof (1963), Brinch Hansen (1970), De Beer (1970) and Vesic (1973). The experimental data on which these equations are based are mostly due to Meyerhof
(1951, 1953, 1963), who tested both prototype and model foundations. There was some additional experimental research following the work of Meyerhof. De Beer (1970) tested very small footings bearing on sand, determining limit bearing capacity from load-settlement curves using the limit load criterion of Brinch Hansen (1963).

In this paper, we present results of rigorous analyses that we employ to obtain values of shape and depth factors for use in bearing capacity computations in sand. The shape and depth factors are determined by computing the bearing capacities of footings of various geometries placed at various depths and comparing those with the bearing capacities of strip footings located on the ground surface for the same soil properties (unit weight and friction angle). In addition to revisiting the terms in the traditional bearing capacity equation and proposing new, improved relationships, we shall also propose a different form of the bearing capacity equation, a simpler form, that does not require an assumption of independence of the self-weight and surcharge effects. This new form of the bearing capacity equation consists of one term instead of two.

\section{CALCULATION OF LIMIT BEARING CAPACITY USING LIMIT ANALYSIS \\ Limit analysis: background \\ From the time Hill (1951) and Drucker et al. (1951,1952)} published their ground-breaking lower and upper-bound theorems of plasticity theory, on which limit analysis is based, it was apparent that limit analysis would be a tool that would provide important insights into the bearing capacity problem and other stability applications. However, the numerical techniques required for finding very close lower and upper bounds on collapse loads, thus accurately estimating the collapse loads themselves, were not available until very recently.

Table 1. Commonly used expressions for shape factors

\begin{tabular}{l|c|c}
\hline & $q_{0}$ term & $\gamma$ term \\
\hline Meyerhof (1963) & $s_{\mathrm{q}}=1+0 \cdot 1 N \frac{B}{L}$ & $s_{\gamma}=1+0 \cdot 1 N \frac{B}{L}$ \\
Brinch Hansen (1970) & $s_{\mathrm{q}}=1+\frac{B}{L} \sin \phi$ & $s_{\gamma}=1-0 \cdot 4 \frac{B}{L} \geqslant 0 \cdot 6$ \\
Vesic (1973) & $s_{\mathrm{q}}=1+\frac{B}{L} \tan \phi$ & $s_{\gamma}=1-0 \cdot 4 \frac{B}{L} \geqslant 0 \cdot 6$ \\
\hline
\end{tabular}

$N=$ flow number $=\tan ^{2}(45+\phi / 2)$.

Table 2. Commonly used expressions for depth factors

\begin{tabular}{l|c|c}
\hline & $q_{0}$ term & $\gamma$ term \\
\hline Meyerhof (1963) & $d_{\mathrm{q}}=1+0 \cdot 1 \sqrt{N} \frac{D}{B}$ & $d_{\gamma}=1+0 \cdot 1 \sqrt{N} \frac{D}{B}$ \\
Brinch Hansen (1970) & $D / B \leqslant 1:$ & $d_{\gamma}=1$ \\
and Vesic (1973) & $d_{\mathrm{q}}=1+2 \tan \phi(1-\sin \phi)^{2} \frac{D}{B}$ \\
$D / B>1$ & \\
& $d_{\mathrm{q}}=1+2 \tan \phi(1-\sin \phi)^{2} \tan ^{-1} \frac{D}{B}$ & \\
\hline
\end{tabular}

$N=$ flow number $=\tan ^{2}(45+\phi / 2)$ 
Limit analysis takes advantage of the lower- and upperbound theorems of plasticity theory to bound the rigorous solution to a stability problem from below and above. The theorems are based on the principle of maximum power

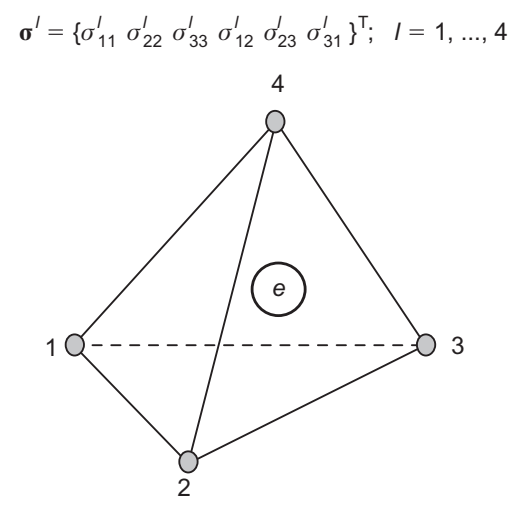

(a)

$$
\begin{aligned}
& \boldsymbol{\sigma}^{e}=\left\{\begin{array}{llllll}
\sigma_{11}^{e} & \sigma_{22}^{e} & \sigma_{33}^{e} & \sigma_{12}^{e} & \sigma_{23}^{e} & \sigma_{31}^{e}
\end{array}\right\}^{\top} \\
& \mathbf{u}^{\prime}=\left\{u_{1}^{\prime} u_{2}^{\prime} u_{3}^{\prime}\right\}^{\top} ; I=1, \ldots, 4
\end{aligned}
$$

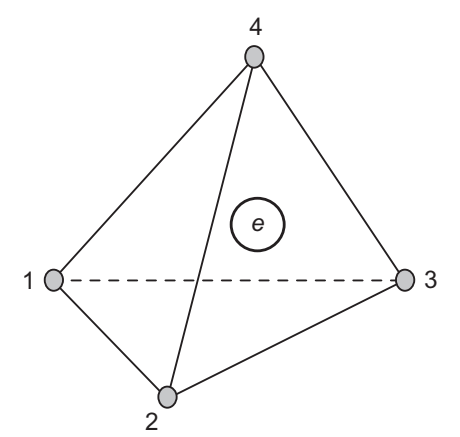

(b)

Fig. 1. Three-dimensional finite elements for: (a) lower-bound analysis; (b) upper-bound analysis

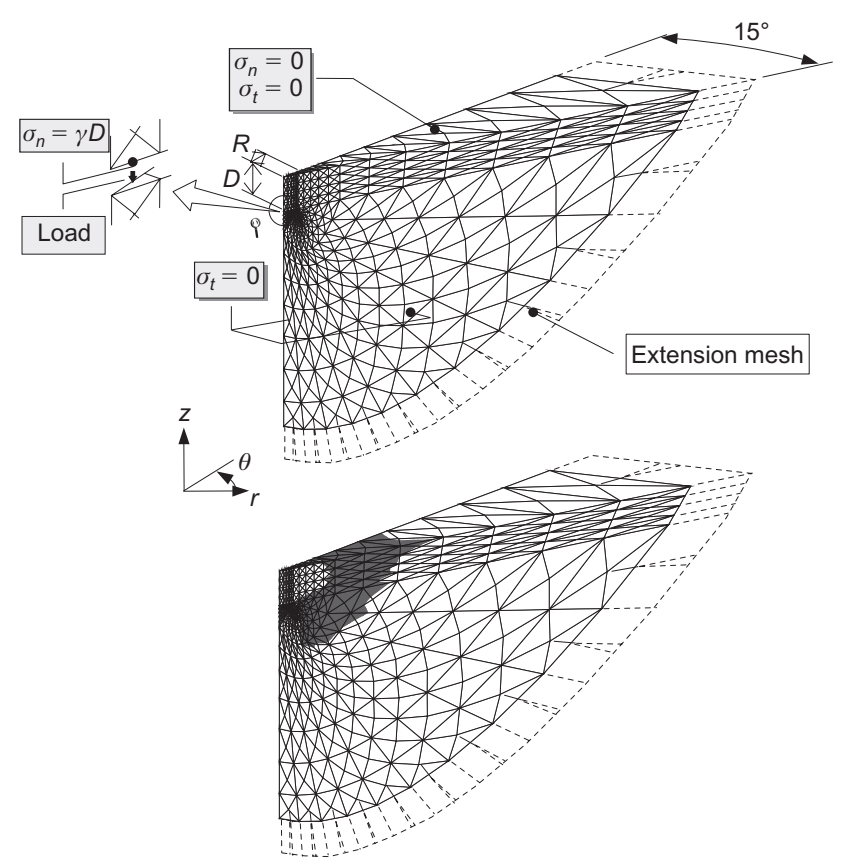

Fig. 2. Typical lower-bound mesh and plasticity zones for circular footings dissipation of plasticity theory, which is valid for soil following an associated flow rule. If soil does not follow an associated flow rule (the case with sands), the bearing capacity values from limit analysis may be too high. The focus of the present paper is on frictional soils following an associated flow rule. However, for relative quantities (such as shape and depth factors), the results produced by limit analysis can be considered reasonable estimates of the quantities for sands.

\section{Discrete formulation of lower-bound theorem}

The objective of a lower-bound calculation is to find a stress field $\sigma_{i j}$ that satisfies equilibrium throughout the soil

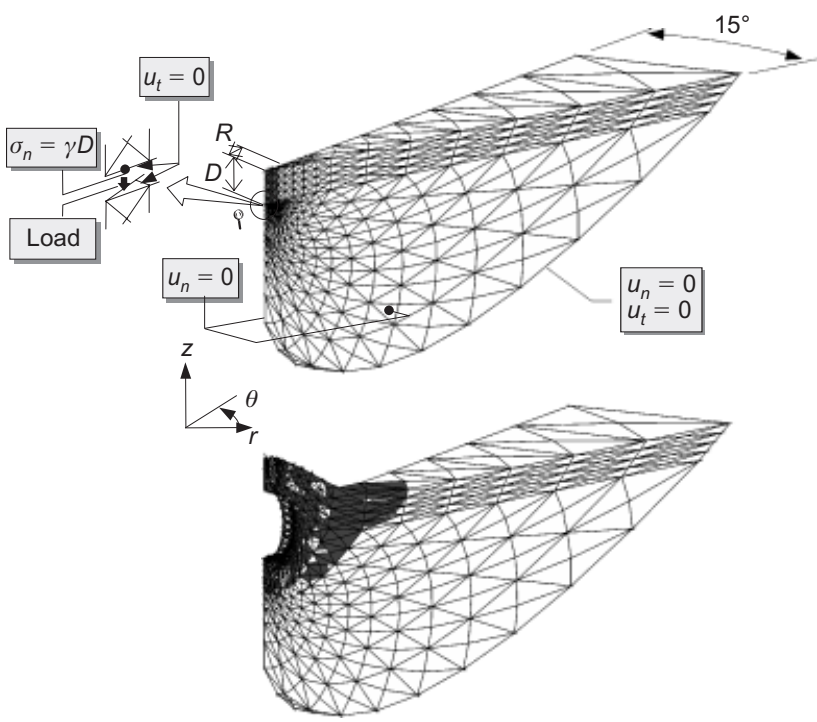

Fig. 3. Typical upper-bound mesh and deformation pattern for circular footings

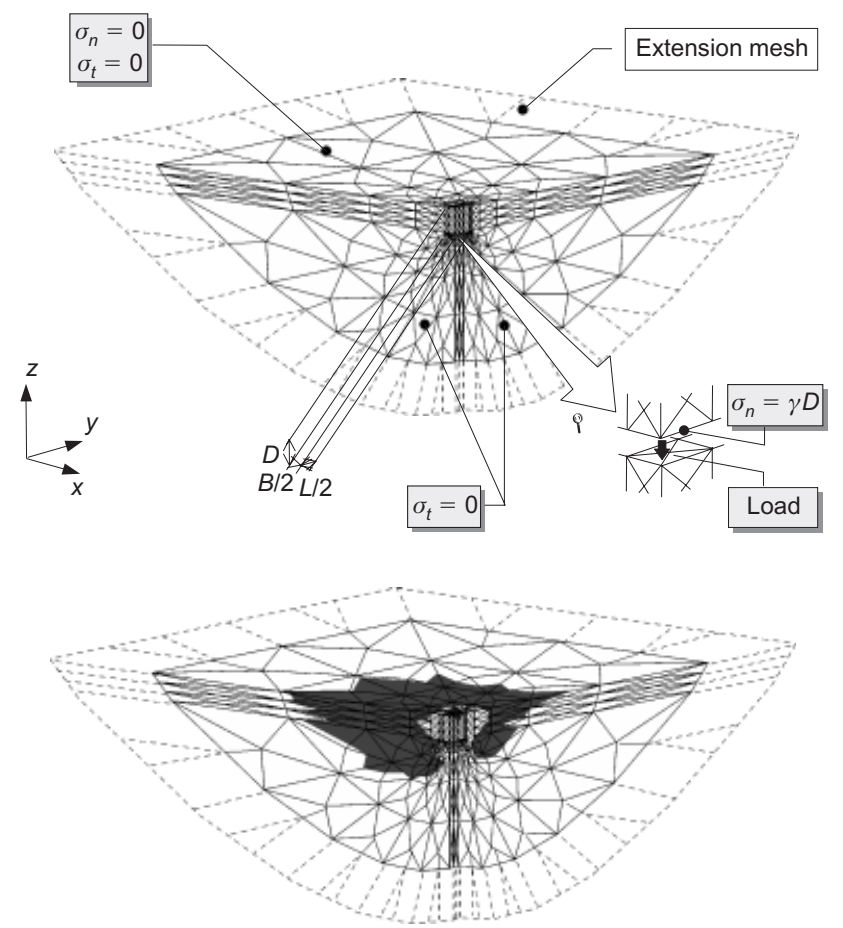

Fig. 4. Typical lower-bound mesh and plasticity zones for rectangular footings 


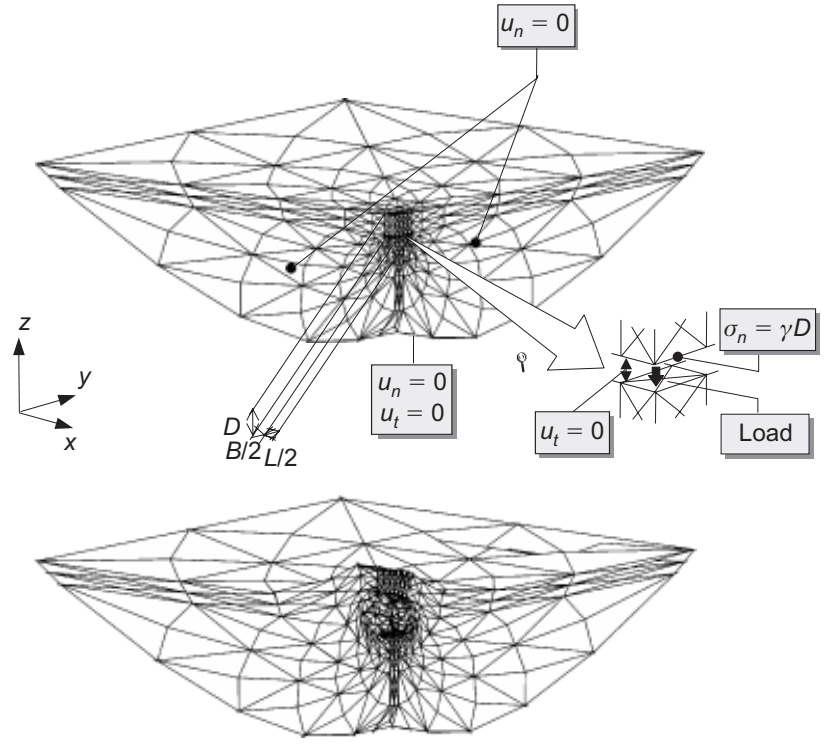

Fig. 5. Typical upper-bound mesh and deformation pattern for rectangular footings mass, balances the prescribed surface tractions, nowhere violates the yield criterion, and maximises $Q$, given in the general case by

$$
Q=\int_{S} \mathbf{T} \mathrm{d} S+\int_{V} \mathbf{X} \mathrm{d} V
$$

where $\mathbf{T}$ and $\mathbf{X}$ are, respectively, the surface tractions and body forces. In our analyses, body forces (soil weight) are prescribed: therefore equation (8) reduces to the first integral only.

The numerical implementation of the limit analysis theorems usually proceeds by discretising the continuum into a set of finite elements and then using mathematical programming techniques to solve the resulting optimisation problem. The choice of finite elements that can be employed to guarantee a rigorous lower-bound numerical formulation is rather limited. They must be linear stress elements. Additionally, consideration of equilibrium of any two elements sharing a face does not lead to a requirement of continuity of the normal stress in a direction parallel to the shared face (Fig. 1(a)). In the present analysis, these stress discontinu-
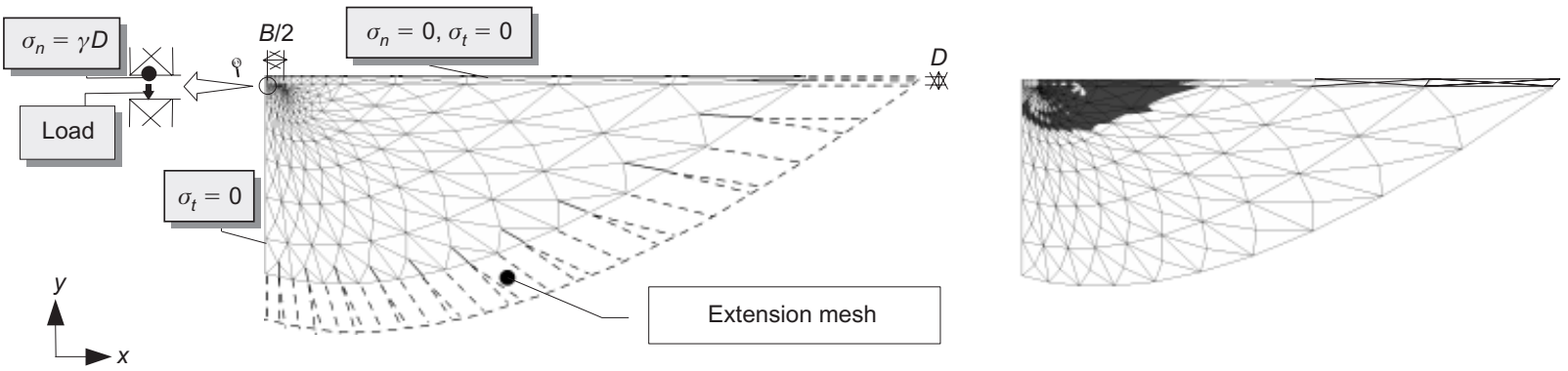

(a)
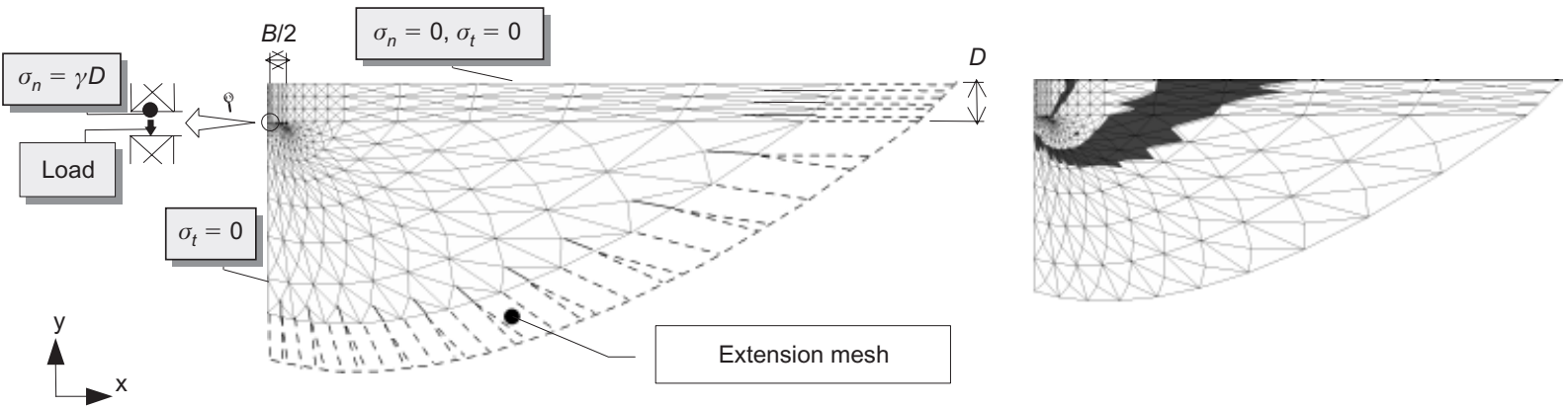

(b)

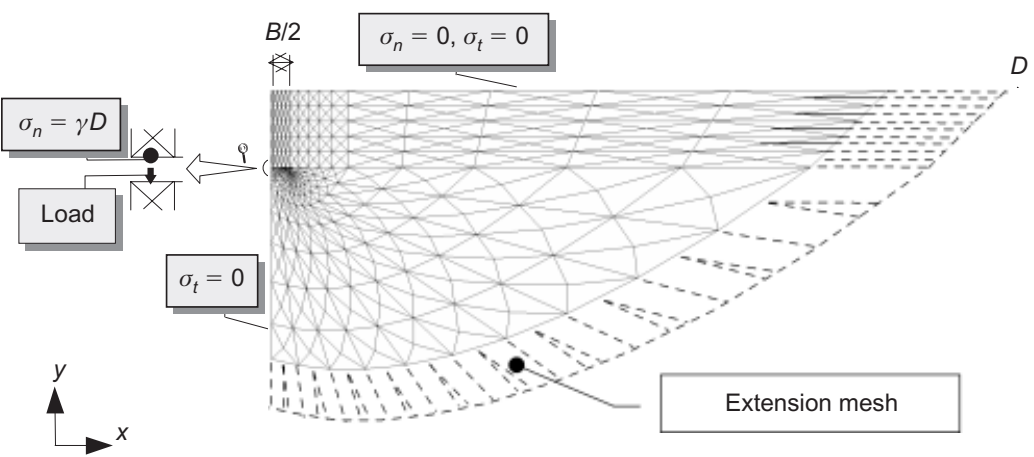

(c)

Fig. 6. Lower-bound mesh and plasticity zones for strip footing with: (a) $D / B=0 \cdot 2 ;(b) D / B=1 \cdot 0 ;(c) D / B=2 \cdot 0$ 
ities are placed between all elements. If $D$ is the problem dimensionality, then there are $D+1$ nodes in each element, and each node is associated with a $\left(D^{2}+D\right) / 2$-dimensional vector of stress variables $\left\{\sigma_{i j}\right\}, i=1, \ldots, D ; j=i, \ldots, D$. These stresses are taken as the problem variables.

A detailed description of the numerical formulation of the lower-bound theorem utilised in the present study is beyond the scope of the paper, but can be found in Lyamin (1999) and Lyamin \& Sloan (2002a).

\section{Discrete formulation of upper-bound theorem}

The objective of an upper-bound calculation is to find a velocity distribution $\mathbf{u}$ that satisfies compatibility, the flow rule and the velocity boundary conditions, and which minimises the internal power dissipation less the rate of work done by prescribed external forces:

$$
W_{1}=\int_{V} \boldsymbol{\sigma} \dot{\boldsymbol{\varepsilon}} \mathrm{d} V-\int_{S} \mathbf{T}_{\mathrm{p}}^{\mathrm{T}} \mathbf{u} \mathrm{d} S-\int_{V} \mathbf{X}_{\mathrm{p}}^{\mathrm{T}} \mathbf{u} \mathrm{d} V
$$

An upper-bound estimate on the true collapse load can be obtained by equating $W_{1}$ to the rate of work done by all other external loads, given by

$$
W_{2}=\int_{S} \mathbf{T}^{\mathrm{T}} \mathbf{u} \mathrm{d} S+\int_{V} \mathbf{X}^{\mathrm{T}} \mathbf{u} \mathrm{d} V
$$

For a cohesionless soil there is no energy dissipation. In a bearing capacity problem, this means that the bearing capacity comes entirely from the self-weight of the soil. Additionally, minimisation of $W_{1}$ implies maximisation of $W_{2}$, which is due entirely to the tractions applied on the soil mass by the footing.

In contrast to the lower-bound formulation, there is more than one type of finite element that will enforce rigorous upper-bound calculations (e.g. Yu et al., 1994; Makrodimopoulos \& Martin, 2005). In the present work, we use the simplex finite element illustrated in Fig. 1(b). Kinematically admissible velocity discontinuities are permitted at all interfaces between adjacent elements. If $D$ is the dimensionality of the problem, then there are $D+1$ nodes in the element, and each node is associated with a $D$-dimensional vector of velocity variables $\left\{u_{i}\right\}, i=1, \ldots, D$. These, together with a $\left(D^{2}+D\right) / 2$-dimensional vector of elemental stresses $\left\{\sigma_{i j}\right\}$, $i=1, \ldots, D ; j=i, \ldots, D$, and a $2(D-1)$-dimensional vector of discontinuity velocity variables $v^{\mathrm{d}}$ are taken as the problem variables.

A comprehensive description of the dimensionally independent upper-bound formulation (suitable for cohesive-
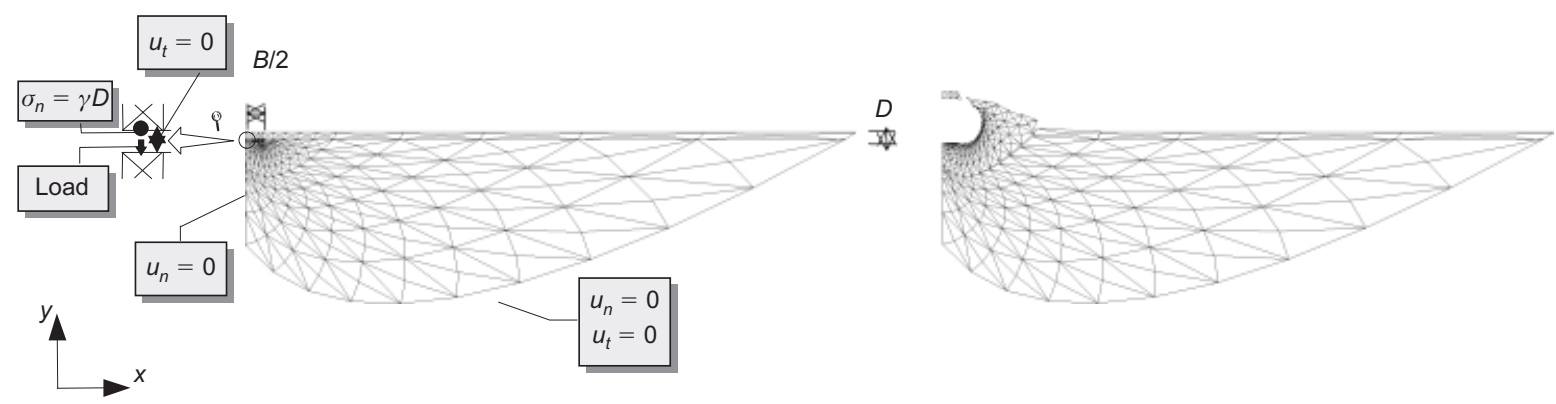

(a)
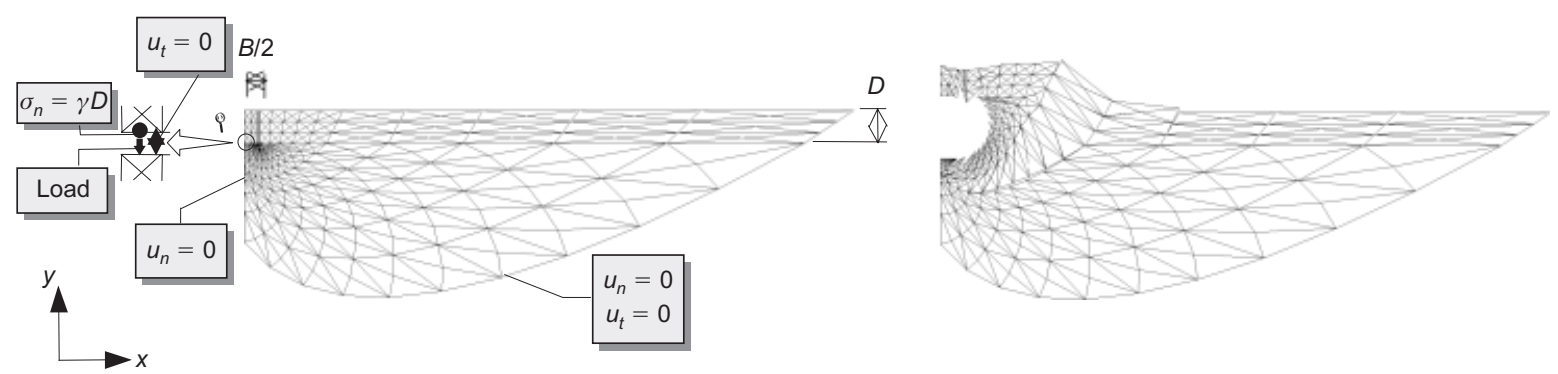

(b)
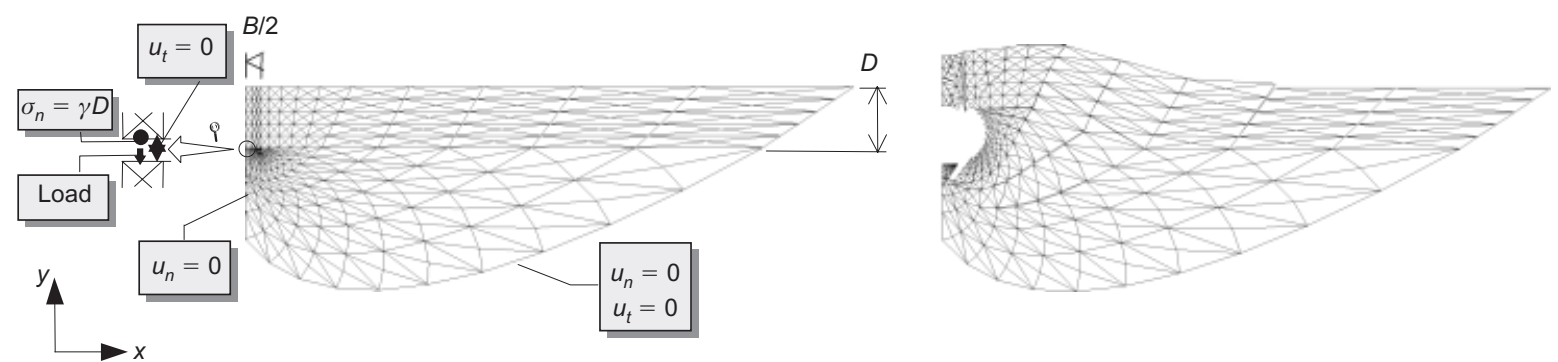

(c)

Fig. 7. Upper-bound mesh and deformation pattern for strip footing with: (a) $D / B=0 \cdot 2 ;$ (b) $D / B=1 \cdot 0 ;($ c) $D / B=2 \cdot 0$ 
frictional materials) used to carry out computations for this research is given in Lyamin \& Sloan (2002b), Lyamin et al. (2005) and Krabbenhøft et al. (2005).

\section{TYPICAL MESHES FOR EMBEDDED FOOTING PROBLEM}

To increase the accuracy of the computed depth and shape factors for 3D footings, the symmetry inherent in all of these problems is fully exploited. This means that only $15^{\circ}, 45^{\circ}$ and $90^{\circ}$ sectors are discretised for the circular, square and rectangular footings respectively, as shown in Figs 2-7. These plots also show the boundary conditions adopted in the various analyses and resultant plasticity zones (shown as shaded in the figures) and deformation patterns. The $15^{\circ}$ sector for circular footings has been used to minimise computation time. A slice with such a thickness can be discretised using only one layer of well-shaped elements, while keeping the error in geometry representation below $1 \%$ (which is approximately five times less than the accuracy of the predicted collapse load, as we shall see later).

For the lower-bound meshes, special extension elements are included to extend the stress field over the semi-infinite domain (thus guaranteeing that the solutions obtained are rigorous lower bounds on the true solutions; Pastor, 1978). To model the embedded conditions properly, the space above the footing was filled with soil. At the same time, the model includes a gap between the top of the footing and this fill; this gap is supported by normal hydrostatic pressure, as shown in the enlarged diagrams of Figs 2-7. Rough condi- tions are applied at the top and bottom of the footing by prescribing zero tangential velocity for upper-bound calculations and specifying no particular shear stresses for lowerbound calculations (that is, the yield criterion is operative between the footing and the soil in the same way as it is operative within the soil). This modelling strategy is geometrically simple, producing a result that is close to the desired quantity (pure unit base resistance) with only a slight conservative bias when compared with other possible modelling options, shown in Fig. 8.

In order to illustrate the differences between results from the different options, we performed a model comparison study, which is summarised in Table 3. For each option, the lower (LB), upper (UB) and average (Avg) values of collapse pressure were computed using $\mathrm{FE}$ meshes similar to those shown in Figs 6 and 7. From the results presented in Table 3, it is apparent that a simple 'rigid-block' model is on the unsafe side when 'rough' walls are assumed, and is too conservative when 'smooth' walls are assumed, when compared with realistically shaped footings. On the other hand, the 'rigid-plate' model with hydrostatically supported soil above the plate is safe for all considered $D / B$ ratios and has the lowest geometric complexity (which is especially helpful in modelling 3D cases). Note, however, that the differences between the results of all the analyses are not large, even for the maximum $D / B$ value considered in the calculations. The difference between all considered footing geometries and wall/soil interface conditions (for a rough base in all cases) is not greater than $14 \%$. If we exclude the 'rigid-

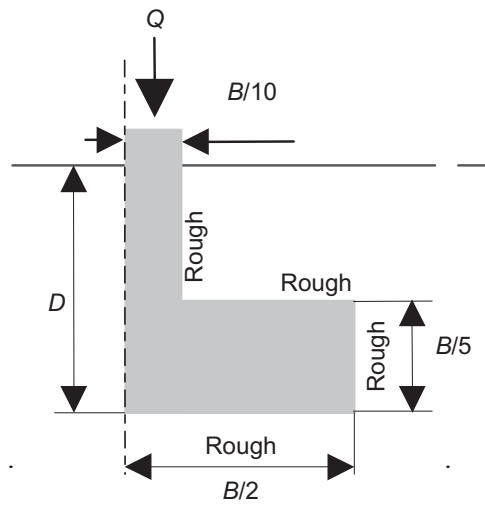

(a)

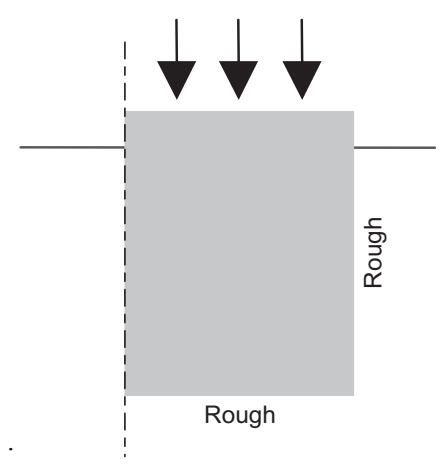

(e)

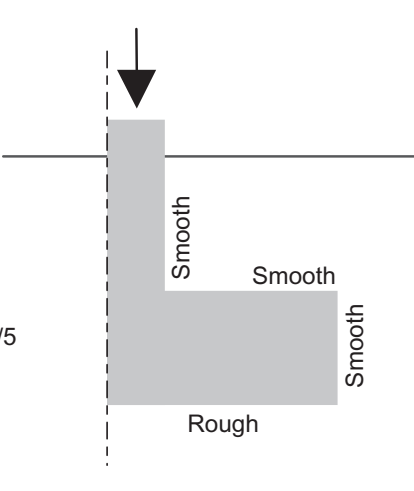

(b)

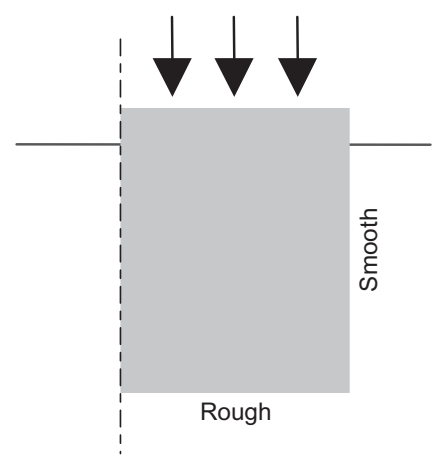

(f)

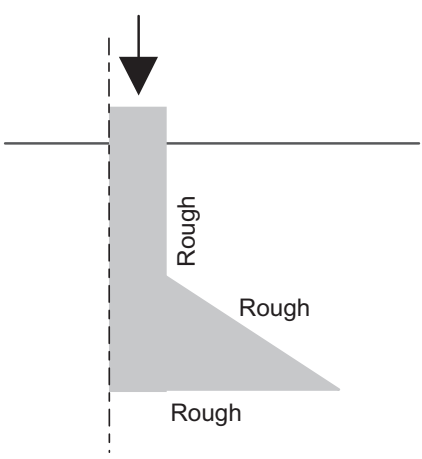

(c)

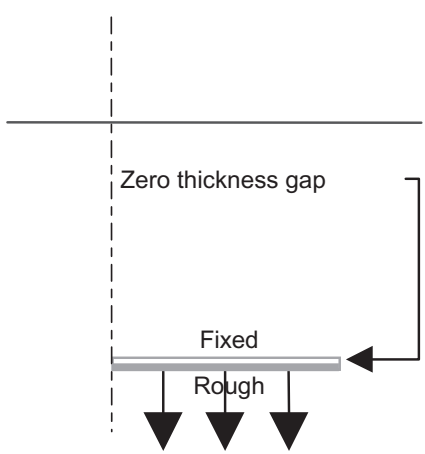

(g)

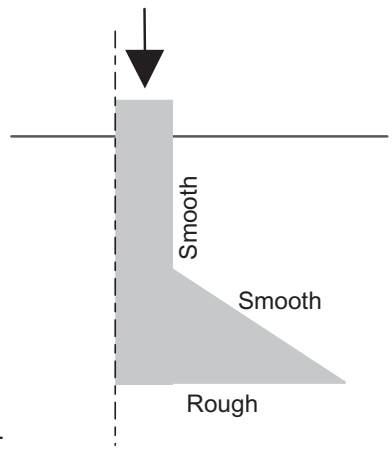

(d)

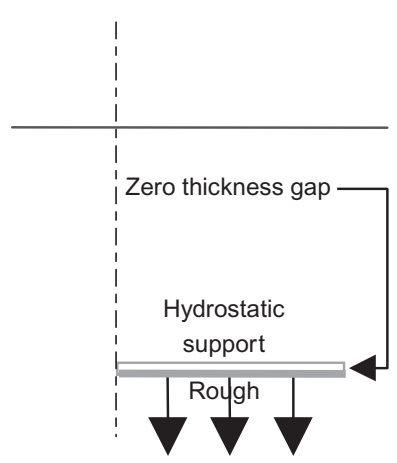

(h)

Fig. 8. Modelling options for embedded 2D footing: (a) T-bar, rough base, rough walls; (b) T-bar, rough base, smooth walls; (c) Tcone, rough base, rough walls; (d) T-cone, rough base, smooth walls; (e) block, rough base, rough walls; (f) block, rough base, smooth walls; (g) plate, rough base, fixed top; (h) plate, rough base, hydrostatically supported top 
block' model, this figure drops to just $5 \%$ for the maximum $D / B$ ratio considered.

\section{DETERMINATION OF THE TRADITIONAL BEARING CAPACITY EQUATION TERMS \\ Range of conditions considered in the calculations}

Our goal in this section is to generate equations for shape and depth factors that will perform the same function as the equations in Tables 1 and 2, but will do so with greater accuracy. The range of friction angles of sands is from roughly $27^{\circ}$ to about $45^{\circ}$ for square and circular footings, and from $27^{\circ}$ to about $50^{\circ}$ for strip footings, to which planestrain friction angles apply. Accordingly, the frictional soils considered in our calculations have $\phi=25^{\circ}, 30^{\circ}, 35^{\circ}, 40^{\circ}$ and $45^{\circ}$.

We are interested in both circular and square footings. In practice, most rectangular footings have $L / B$ of no more than 4 , where $L$ and $B$ are the two plan dimensions of the footing. Accordingly, our calculations are for footings with $L / B=1,2,3$ and 4 . The maximum embedment for shallow foundations is typically taken as $D=B$. We more liberally established 2 as the upper limit of the $D / B$ range considered in our calculations. The embedment ratios we considered were $0 \cdot 1,0 \cdot 2,0 \cdot 4,0 \cdot 6,0 \cdot 8,1$ and 2 .

\section{Determination of $N_{\gamma}$}

The very first step in this process of analysis of the bearing capacity equation is the determination of $N_{\gamma}$, which requires the determination of lower and upper bounds on the bearing capacity of a strip footing on the surface of a frictional soil. Equation (1) is rewritten for this case as

$$
q_{\mathrm{bL}}=\frac{1}{2} \gamma B N_{\gamma}
$$

Calculations were done with $\gamma=1$ and $B=2$ so that $q_{\mathrm{bL}}$ resulted numerically equal to $N_{\gamma}$. The lower- and upperbound values of $N_{\gamma}$ calculated in this way using limit analysis are shown in Table 4 and Fig. 9, which also show the values calculated using equations (5), (6) and (7). For completeness, the table also shows the value of $N_{\mathrm{q}}$ for each friction angle. It can be seen that the values of $N_{\gamma}$ calculated using equation (5) fall between the lower and upper bounds on $N_{\gamma}$ for $\phi$ values lower than $40^{\circ}$ and then fall below the lower bound for $\phi \geqslant 40^{\circ}$. Values of $N_{\gamma}$ calculated using equation (7) fall within the range determined by lower- and upper-bound solutions for all $\phi$ values of interest. On the other hand, the $N_{\gamma}$ values calculated using equation (6) are too high. So this equation, the Caquot \& Kerisel (1953) equation, is not correct, and its use should be discouraged.

\section{Determination of the depth factors}

The depth factor $d_{\gamma}$ was taken as 1 by both Vesic (1973) and Brinch Hansen (1970), as seen in Table 2. Conceptually, a value of $d_{\gamma}=1$ means that the $N_{\gamma}$ term refers only to the slip mechanism that forms below the base of the footing. This means that the effects of the portion of the mechanism extending above the base of the footing are fully captured by the depth factor $d_{\mathrm{q}}$. In this section, consistent with what has traditionally been done, we take $d_{\gamma}=1$ as well. Later in the paper we shall present an alternative way to account for embedment of the footing.

For the determination of $d_{\mathrm{q}}$, we consider a strip footing at depth. For this case, equation (1) becomes 
Table 4. Values of $N_{\mathrm{q}}$ and $N_{\gamma}$ calculated using limit analysis and equations (5), (6) and (7).

\begin{tabular}{|c|c|c|c|c|c|c|c|c|c|c|}
\hline \multirow[t]{2}{*}{$\phi$} & \multirow[t]{2}{*}{$N_{\mathrm{q}}$} & \multicolumn{3}{|c|}{$N_{\gamma}$} & \multirow[t]{2}{*}{$N_{\gamma}$ (Martin) } & \multirow[t]{2}{*}{$N_{\gamma}(\mathrm{LB})$} & \multirow[t]{2}{*}{$N_{\gamma}(\mathrm{UB})$} & \multirow[t]{2}{*}{ Error: \% } & \multirow[t]{2}{*}{$N_{\gamma, \mathrm{w}}$} & \multirow[t]{2}{*}{ Error: \% } \\
\hline & & Equation (5) & Equation (6) & Equation (7) & & & & & & \\
\hline $25^{\circ}$ & $10 \cdot 66$ & $6 \cdot 76$ & $10 \cdot 88$ & $6 \cdot 49$ & $6 \cdot 49$ & $6 \cdot 44$ & $7 \cdot 09$ & $4 \cdot 80$ & $6 \cdot 72$ & $3 \cdot 57$ \\
\hline $30^{\circ}$ & 18.40 & 15.07 & $22 \cdot 40$ & 14.75 & 14.75 & $14 \cdot 57$ & 15.90 & $4 \cdot 36$ & $15 \cdot 51$ & $5 \cdot 18$ \\
\hline $35^{\circ}$ & $33 \cdot 30$ & 33.92 & 48.03 & 34.48 & 34.48 & 33.81 & 36.98 & $4 \cdot 48$ & $35 \cdot 01$ & 1.54 \\
\hline $40^{\circ}$ & $64 \cdot 20$ & $79 \cdot 54$ & $109 \cdot 41$ & 85.47 & 85.57 & 82.29 & 91.86 & $5 \cdot 50$ & 89.94 & $5 \cdot 10$ \\
\hline $45^{\circ}$ & $134 \cdot 87$ & $200 \cdot 81$ & $271 \cdot 75$ & $234 \cdot 2$ & $234 \cdot 21$ & $221 \cdot 71$ & 255.44 & $7 \cdot 07$ & $242 \cdot 96$ & 3.74 \\
\hline
\end{tabular}

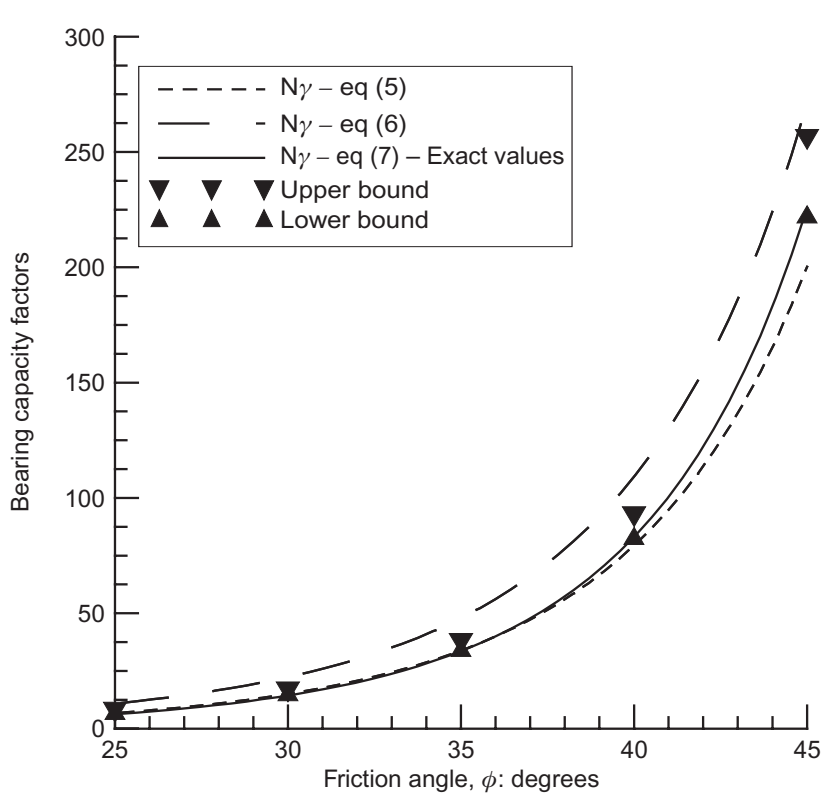

Fig. 9. Bearing capacity factor $N_{\gamma}$ from upper- and lower-bound analyses and from equations due to Brinch Hansen (1970) and Caquot \& Kerisel (1953)

$$
\begin{aligned}
q_{\mathrm{bL}} & =d_{\mathrm{q}} q_{0} N_{\mathrm{q}}+0.5 \gamma B N_{\gamma} \\
& =d_{\mathrm{q}} \gamma D N_{\mathrm{q}}+0.5 \gamma B N_{\gamma}
\end{aligned}
$$

The lower and upper bounds on the second term on the right side of (12) - and indeed the nearly exact value of it are known, as discussed earlier. The corresponding values of $d_{\mathrm{q}}$ can then be calculated from equation (12), rewritten as

$$
d_{\mathrm{q}}=\frac{q_{\mathrm{bL}}-0 \cdot 5 \gamma B N_{\gamma}}{q_{0} N_{\mathrm{q}}}
$$

The results of these calculations, given in Table 5, show clearly that the depth factor $d_{\mathrm{q}}$ does not approach 1 when $D / B \rightarrow 0$, as would be suggested by the expressions given in Table 2. On the contrary, it increases with decreasing $D / B$. This fact can be explained by the inadequacy of the logic of superposition and segregation of the different contributions to bearing capacity. Indeed, the theory of the depth factor $d_{\mathrm{q}}$ is that it would correct for the shear strength of the soil located above the level of the footing base, which disappears upon the replacement of the overburden soil by a surcharge. The reality of the depth factor $d_{\mathrm{q}}$, computed using equation (13), is that it accumulates two contributions. The first contribution is the intended one: the contribution of the shear strength of the soil

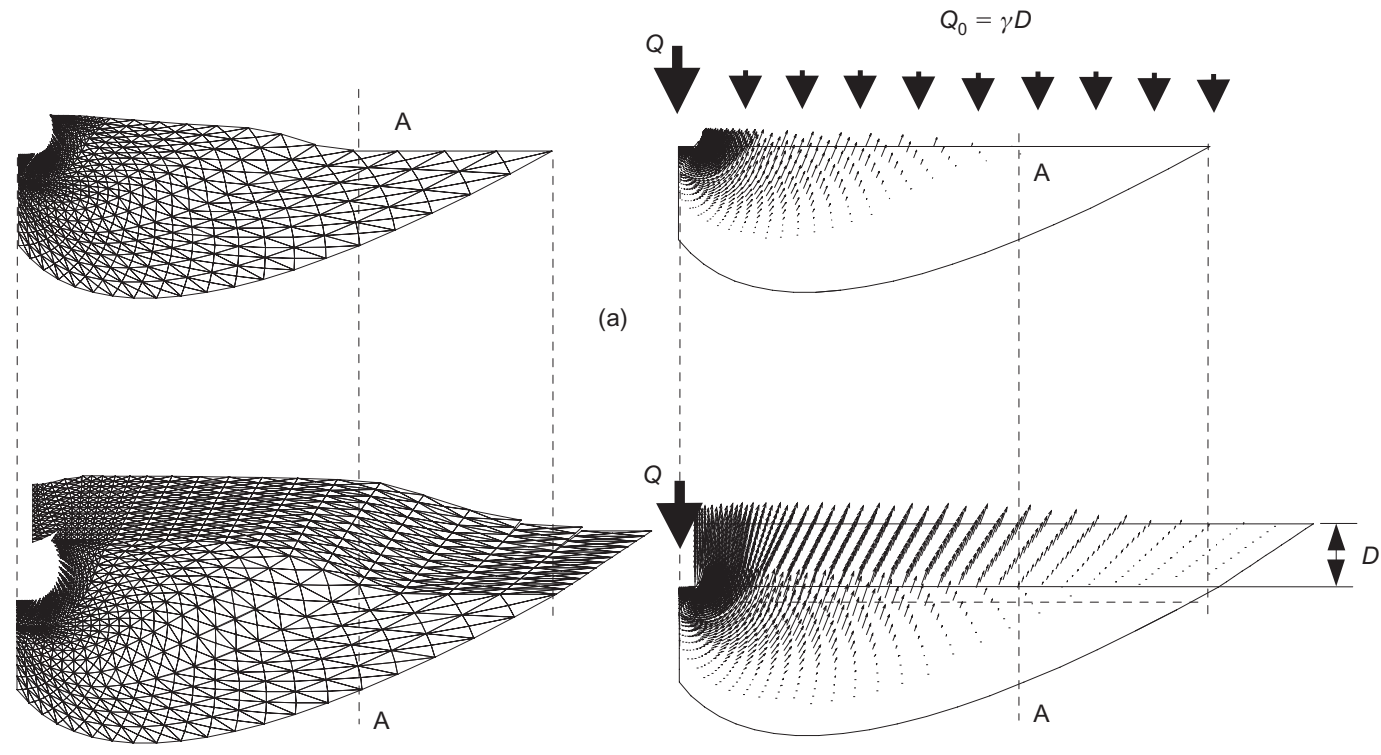

(b)

Fig. 10. Illustration of difference in work done by external forces in two cases: (a) equivalent surcharge used to replace soil above base of footing; (b) footing modelled as an embedded footing 
Table 5. Depth factor $d_{\mathrm{q}}$ (obtained from weighted average of lower and upper bounds on strip footing bearing capacity) for $D=0 \cdot 1$ to $2 B$ and $\phi=25-45^{\circ}$

\begin{tabular}{|c|c|c|c|c|c|c|c|c|c|}
\hline$\phi$ & $D / B$ & $q_{\mathrm{bL}}(\mathrm{LB})$ & $q_{\mathrm{bL}}(\mathrm{UB})$ & $q_{\mathrm{bL}}$ & $q_{0}$ & $q_{0} N_{\mathrm{q}}$ & $0.5 \gamma B N_{\gamma}$ & $d_{\mathrm{q}}$ & Error: $\%$ \\
\hline \multirow[t]{7}{*}{$25^{\circ}$} & $0 \cdot 1$ & $10 \cdot 62$ & 11.07 & $10 \cdot 65$ & $0 \cdot 2$ & $2 \cdot 13$ & $6 \cdot 49$ & 1.95 & $2 \cdot 11$ \\
\hline & $0 \cdot 2$ & $13 \cdot 90$ & $14 \cdot 41$ & 13.94 & $0 \cdot 4$ & $4 \cdot 26$ & $6 \cdot 49$ & $1 \cdot 75$ & $1 \cdot 83$ \\
\hline & $0 \cdot 4$ & $19 \cdot 99$ & $20 \cdot 73$ & $20 \cdot 05$ & $0 \cdot 8$ & $8 \cdot 53$ & $6 \cdot 49$ & $1 \cdot 59$ & $1 \cdot 85$ \\
\hline & 0.6 & $25 \cdot 92$ & $26 \cdot 87$ & 25.99 & $1 \cdot 2$ & $12 \cdot 79$ & $6 \cdot 49$ & $1 \cdot 52$ & $1 \cdot 83$ \\
\hline & $0 \cdot 8$ & 31.93 & $33 \cdot 16$ & $32 \cdot 02$ & $1 \cdot 6$ & $17 \cdot 06$ & $6 \cdot 49$ & $1 \cdot 50$ & 1.92 \\
\hline & $1 \cdot 0$ & $38 \cdot 08$ & $39 \cdot 67$ & $38 \cdot 20$ & $2 \cdot 0$ & $21 \cdot 32$ & $6 \cdot 49$ & 1.49 & $2 \cdot 08$ \\
\hline & $2 \cdot 0$ & $70 \cdot 85$ & 73.95 & 71.09 & $4 \cdot 0$ & $42 \cdot 65$ & $6 \cdot 49$ & $1 \cdot 51$ & $2 \cdot 18$ \\
\hline \multirow[t]{7}{*}{$30^{\circ}$} & $0 \cdot 1$ & $21 \cdot 90$ & $23 \cdot 07$ & $22 \cdot 06$ & $0 \cdot 2$ & $3 \cdot 68$ & $14 \cdot 75$ & 1.99 & $2 \cdot 65$ \\
\hline & $0 \cdot 2$ & $27 \cdot 59$ & $28 \cdot 88$ & $27 \cdot 76$ & $0 \cdot 4$ & $7 \cdot 36$ & $14 \cdot 75$ & $1 \cdot 77$ & $2 \cdot 32$ \\
\hline & 0.4 & $38 \cdot 07$ & 39.91 & $38 \cdot 32$ & $0 \cdot 8$ & $14 \cdot 72$ & $14 \cdot 75$ & $1 \cdot 60$ & $2 \cdot 40$ \\
\hline & 0.6 & $48 \cdot 37$ & $50 \cdot 67$ & 48.68 & $1 \cdot 2$ & $22 \cdot 08$ & $14 \cdot 75$ & $1 \cdot 54$ & $2 \cdot 36$ \\
\hline & $0 \cdot 8$ & $58 \cdot 76$ & 61.47 & $59 \cdot 13$ & $1 \cdot 6$ & $29 \cdot 44$ & $14 \cdot 75$ & $1 \cdot 51$ & $2 \cdot 29$ \\
\hline & $1 \cdot 0$ & $69 \cdot 21$ & $72 \cdot 81$ & $69 \cdot 70$ & $2 \cdot 0$ & $36 \cdot 80$ & $14 \cdot 75$ & 1.49 & $2 \cdot 58$ \\
\hline & $2 \cdot 0$ & $125 \cdot 44$ & $132 \cdot 52$ & $126 \cdot 40$ & $4 \cdot 0$ & $73 \cdot 60$ & $14 \cdot 75$ & $1 \cdot 52$ & $2 \cdot 80$ \\
\hline \multirow[t]{7}{*}{$35^{\circ}$} & $0 \cdot 1$ & 46.99 & $50 \cdot 04$ & $47 \cdot 63$ & $0 \cdot 2$ & $6 \cdot 66$ & $34 \cdot 48$ & 1.98 & $3 \cdot 20$ \\
\hline & $0 \cdot 2$ & $57 \cdot 29$ & $60 \cdot 89$ & $58 \cdot 05$ & $0 \cdot 4$ & $13 \cdot 32$ & $34 \cdot 48$ & $1 \cdot 77$ & $3 \cdot 10$ \\
\hline & $0 \cdot 4$ & $76 \cdot 49$ & $81 \cdot 09$ & $77 \cdot 46$ & $0 \cdot 8$ & $26 \cdot 64$ & $34 \cdot 48$ & $1 \cdot 61$ & $2 \cdot 97$ \\
\hline & 0.6 & $95 \cdot 11$ & $100 \cdot 74$ & $96 \cdot 30$ & $1 \cdot 2$ & 39.96 & $34 \cdot 48$ & $1 \cdot 55$ & $2 \cdot 92$ \\
\hline & $0 \cdot 8$ & $113 \cdot 46$ & $120 \cdot 65$ & $114 \cdot 98$ & $1 \cdot 6$ & $53 \cdot 27$ & $34 \cdot 48$ & $1 \cdot 51$ & $3 \cdot 13$ \\
\hline & $1 \cdot 0$ & $132 \cdot 07$ & $140 \cdot 95$ & $133 \cdot 95$ & $2 \cdot 0$ & $66 \cdot 59$ & $34 \cdot 48$ & 1.49 & $3 \cdot 31$ \\
\hline & $2 \cdot 0$ & $232 \cdot 93$ & $248 \cdot 15$ & $236 \cdot 15$ & $4 \cdot 0$ & $133 \cdot 18$ & $34 \cdot 48$ & $1 \cdot 51$ & $3 \cdot 22$ \\
\hline \multirow[t]{7}{*}{$40^{\circ}$} & $0 \cdot 1$ & $108 \cdot 09$ & $117 \cdot 84$ & $111 \cdot 43$ & $0 \cdot 2$ & $12 \cdot 84$ & $85 \cdot 57$ & $2 \cdot 01$ & $4 \cdot 37$ \\
\hline & $0 \cdot 2$ & $128 \cdot 53$ & $139 \cdot 60$ & $132 \cdot 32$ & $0 \cdot 4$ & $25 \cdot 68$ & $85 \cdot 57$ & $1 \cdot 82$ & $4 \cdot 18$ \\
\hline & $0 \cdot 4$ & $165 \cdot 62$ & $179 \cdot 30$ & $170 \cdot 31$ & $0 \cdot 8$ & $51 \cdot 36$ & $85 \cdot 57$ & $1 \cdot 65$ & $4 \cdot 02$ \\
\hline & 0.6 & $201 \cdot 32$ & $217 \cdot 82$ & $206 \cdot 98$ & $1 \cdot 2$ & $77 \cdot 03$ & $85 \cdot 57$ & $1 \cdot 58$ & $3 \cdot 99$ \\
\hline & $0 \cdot 8$ & $237 \cdot 00$ & $256 \cdot 76$ & 243.77 & $1 \cdot 6$ & $102 \cdot 71$ & $85 \cdot 57$ & $1 \cdot 54$ & $4 \cdot 05$ \\
\hline & $1 \cdot 0$ & $273 \cdot 13$ & $295 \cdot 84$ & $280 \cdot 91$ & $2 \cdot 0$ & $128 \cdot 39$ & $85 \cdot 57$ & $1 \cdot 52$ & $4 \cdot 04$ \\
\hline & $2 \cdot 0$ & $463 \cdot 99$ & $499 \cdot 86$ & $476 \cdot 28$ & $4 \cdot 0$ & $256 \cdot 78$ & $85 \cdot 57$ & $1 \cdot 52$ & $3 \cdot 77$ \\
\hline \multirow[t]{7}{*}{$45^{\circ}$} & $0 \cdot 1$ & $277 \cdot 45$ & $312 \cdot 38$ & $290 \cdot 39$ & $0 \cdot 2$ & $26 \cdot 97$ & $234 \cdot 21$ & $2 \cdot 08$ & $6 \cdot 01$ \\
\hline & $0 \cdot 2$ & $321 \cdot 10$ & $360 \cdot 05$ & $335 \cdot 53$ & $0 \cdot 4$ & 53.95 & $234 \cdot 21$ & $1 \cdot 88$ & $5 \cdot 80$ \\
\hline & $0 \cdot 4$ & $401 \cdot 50$ & $447 \cdot 54$ & $418 \cdot 56$ & $0 \cdot 8$ & $107 \cdot 90$ & $234 \cdot 21$ & $1 \cdot 71$ & $5 \cdot 50$ \\
\hline & 0.6 & $479 \cdot 00$ & $531 \cdot 41$ & $498 \cdot 42$ & $1 \cdot 2$ & $161 \cdot 85$ & $234 \cdot 21$ & 1.63 & $5 \cdot 26$ \\
\hline & $0 \cdot 8$ & $555 \cdot 46$ & $614 \cdot 58$ & $577 \cdot 37$ & $1 \cdot 6$ & $215 \cdot 80$ & $234 \cdot 21$ & $1 \cdot 59$ & $5 \cdot 12$ \\
\hline & $1 \cdot 0$ & $631 \cdot 77$ & $696 \cdot 15$ & $655 \cdot 63$ & $2 \cdot 0$ & $269 \cdot 75$ & $234 \cdot 21$ & $1 \cdot 56$ & $4 \cdot 91$ \\
\hline & $2 \cdot 0$ & $1019 \cdot 70$ & $1117 \cdot 08$ & $1055 \cdot 79$ & $4 \cdot 0$ & $539 \cdot 50$ & $234 \cdot 21$ & $1 \cdot 52$ & $4 \cdot 61$ \\
\hline
\end{tabular}

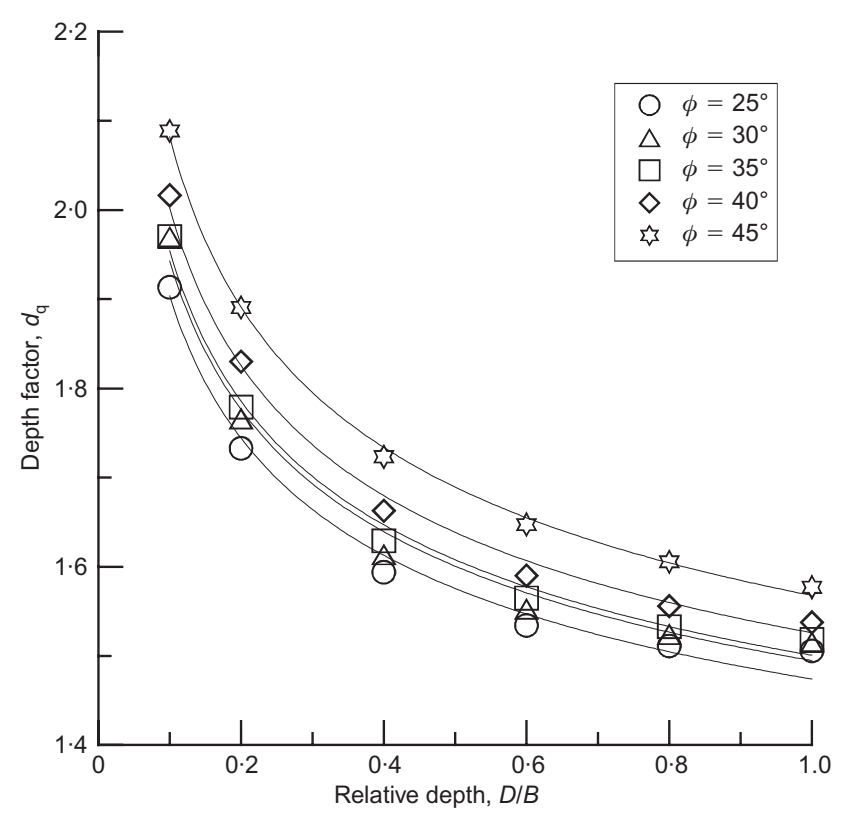

Fig. 11. Depth factor $d_{\mathrm{q}}$ against depth for various friction angles located above the level of the footing base, which is lost upon its replacement by an equivalent surcharge. The second contribution results from the fact that replacing the soil above the footing base by an equivalent surcharge produces a different response of the soil below the footing base. Note that this is contrary to the assumption that the response of the soil below the footing base is independent of what happens above it (which is the logic behind making $d_{\gamma}=1$ ). Fig. 10 shows, using upper-bound calculations, that the rate of work done by displacing the soil above the level of an embedded footing must be greater than the rate of work done against an equivalent surface footing (i.e. the footing plus a surcharge equivalent to the overburden pressure associated with the embedment). This is seen by the larger extent of the collapse mechanism in the presence of soil above the footing base compared with that for an equivalent surface footing. To visualise this, one can compare Fig. 10(a) and Fig. 10(b). It can be seen from this comparison that no displacement of the soil is occurring on the right side of line $\mathrm{A}-\mathrm{A}$ for the case in which a surcharge load is used: so A-A marks the boundary of the collapse mechanism in that case. However, there is considerable displacement of soil to the right of $\mathrm{A}-\mathrm{A}$ for the case of the embedded footing. So the fact that there is a soil-on-soil interaction at the 
Table 6. Lower and upper bounds on shape factors and their weighted averages.

Circular footing

\begin{tabular}{|c|c|c|c|c|c|c|c|c|c|c|}
\hline$\phi$ & $N_{\gamma}$ & $s_{\gamma} N_{\gamma}$ (LB) & $s_{\gamma}(\mathrm{LB})$ & $s_{\gamma} N_{\gamma}$ (UB) & $s_{\gamma}(\mathrm{UB})$ & $\Delta \mathrm{UB} / \Delta \mathrm{LB}$ & $w(\mathrm{LB})$ & $w(\mathrm{UB})$ & $s_{\gamma} N_{\gamma, \mathrm{w}}$ & $s_{\gamma, \mathrm{w}}$ \\
\hline $25^{\circ}$ & $6 \cdot 49$ & $5 \cdot 65$ & $0 \cdot 87$ & $8 \cdot 26$ & 1.27 & $3 \cdot 57$ & $0 \cdot 78$ & $0 \cdot 22$ & $6 \cdot 22$ & $0 \cdot 96$ \\
\hline $30^{\circ}$ & 14.75 & $14 \cdot 10$ & $0 \cdot 96$ & $19 \cdot 84$ & 1.35 & $2 \cdot 69$ & 0.73 & $0 \cdot 27$ & $15 \cdot 65$ & 1.06 \\
\hline $35^{\circ}$ & $34 \cdot 48$ & $37 \cdot 18$ & 1.08 & $52 \cdot 51$ & 1.52 & 2.69 & 0.73 & 0.27 & $41 \cdot 33$ & 1.20 \\
\hline $40^{\circ}$ & $85 \cdot 57$ & $106 \cdot 60$ & 1.25 & $157 \cdot 21$ & 1.84 & $2 \cdot 41$ & $0 \cdot 71$ & $0 \cdot 29$ & $121 \cdot 45$ & 1.42 \\
\hline $45^{\circ}$ & $234 \cdot 21$ & $338 \cdot 00$ & 1.44 & $539 \cdot 22$ & $2 \cdot 30$ & $2 \cdot 31$ & $0 \cdot 70$ & $0 \cdot 30$ & $398 \cdot 80$ & $1 \cdot 70$ \\
\hline
\end{tabular}

Square footing

\begin{tabular}{|c|c|c|c|c|c|c|c|c|c|c|}
\hline$\phi$ & $N_{\gamma}$ & $s_{\gamma} N_{\gamma}$ (LB) & $s_{\gamma}(\mathrm{LB})$ & $s_{\gamma} N_{\gamma}$ (UB) & $s_{\gamma}(\mathrm{UB})$ & $\Delta \mathrm{UB} / \Delta \mathrm{LB}$ & $w(\mathrm{LB})$ & $w(\mathrm{UB})$ & $s_{\gamma} N_{\gamma, \mathrm{w}}$ & $s_{\gamma, \mathrm{w}}$ \\
\hline $25^{\circ}$ & $6 \cdot 49$ & $5 \cdot 10$ & 0.79 & $9 \cdot 05$ & 1.39 & $4 \cdot 15$ & $0 \cdot 81$ & $0 \cdot 19$ & $5 \cdot 87$ & 0.90 \\
\hline $30^{\circ}$ & 14.75 & 12.67 & 0.86 & $21 \cdot 82$ & 1.48 & 4.03 & $0 \cdot 80$ & $0 \cdot 20$ & $14 \cdot 49$ & 0.98 \\
\hline $35^{\circ}$ & 34.48 & 32.96 & 0.96 & 58.60 & 1.70 & 3.54 & 0.78 & 0.22 & $38 \cdot 61$ & $1 \cdot 12$ \\
\hline $40^{\circ}$ & $85 \cdot 57$ & $91 \cdot 04$ & $1 \cdot 06$ & $184 \cdot 73$ & $2 \cdot 16$ & $3 \cdot 30$ & 0.77 & 0.23 & $112 \cdot 84$ & $1 \cdot 32$ \\
\hline $45^{\circ}$ & $234 \cdot 21$ & $277 \cdot 00$ & $1 \cdot 18$ & 683.09 & $2 \cdot 92$ & 3.63 & 0.78 & 0.22 & $364 \cdot 79$ & 1.56 \\
\hline
\end{tabular}

Rectangular footing, $L / B=1 \cdot 2$

\begin{tabular}{|c|c|c|c|c|c|c|c|c|c|c|}
\hline$\phi$ & $N_{\gamma}$ & $s_{\gamma} N_{\gamma}$ (LB) & $s_{\gamma}(\mathrm{LB})$ & $s_{\gamma} N_{\gamma}$ (UB) & $s_{\gamma}(\mathrm{UB})$ & $\Delta \mathrm{UB} / \Delta \mathrm{LB}$ & $w(\mathrm{LB})$ & $w$ (UB) & $s_{\gamma} N_{\gamma, \mathrm{w}}$ & $s_{\gamma, \mathrm{w}}$ \\
\hline $25^{\circ}$ & $6 \cdot 49$ & $4 \cdot 77$ & 0.73 & $13 \cdot 60$ & $2 \cdot 10$ & $6 \cdot 80$ & $0 \cdot 87$ & $0 \cdot 13$ & 5.90 & 0.91 \\
\hline $30^{\circ}$ & 14.75 & 11.57 & 0.78 & $30 \cdot 31$ & $2 \cdot 05$ & $5 \cdot 22$ & 0.84 & $0 \cdot 16$ & 14.58 & 0.99 \\
\hline $35^{\circ}$ & $34 \cdot 48$ & 28.48 & 0.83 & $79 \cdot 11$ & $2 \cdot 29$ & 3.93 & $0 \cdot 80$ & $0 \cdot 20$ & 38.75 & $1 \cdot 12$ \\
\hline $40^{\circ}$ & 85.57 & 71.91 & $0 \cdot 84$ & 268.98 & $3 \cdot 14$ & 4.44 & $0 \cdot 82$ & $0 \cdot 18$ & $108 \cdot 14$ & $1 \cdot 26$ \\
\hline $45^{\circ}$ & $234 \cdot 21$ & $194 \cdot 70$ & $0 \cdot 83$ & $1013 \cdot 72$ & $4 \cdot 33$ & 3.97 & $0 \cdot 80$ & $0 \cdot 20$ & 359.59 & 1.54 \\
\hline
\end{tabular}

Rectangular footing, $L / B=2$

\begin{tabular}{|c|c|c|c|c|c|c|c|c|c|c|}
\hline$\phi$ & $N_{\gamma}$ & $s_{\gamma} N_{\gamma}(\mathrm{LB})$ & $s_{\gamma}(\mathrm{LB})$ & $s_{\gamma} N_{\gamma}$ (UB) & $s_{\gamma}(\mathrm{UB})$ & $\Delta \mathrm{UB} / \Delta \mathrm{LB}$ & $w(\mathrm{LB})$ & $w(\mathrm{UB})$ & $s_{\gamma} N_{\gamma, \mathrm{w}}$ & $s_{\gamma, \mathrm{w}}$ \\
\hline $25^{\circ}$ & $6 \cdot 49$ & $5 \cdot 10$ & 0.79 & $12 \cdot 47$ & 1.92 & 5.99 & $0 \cdot 86$ & $0 \cdot 14$ & $6 \cdot 15$ & 0.95 \\
\hline $30^{\circ}$ & $14 \cdot 75$ & $12 \cdot 10$ & 0.82 & $27 \cdot 57$ & $1 \cdot 87$ & $4 \cdot 44$ & $0 \cdot 82$ & $0 \cdot 18$ & $14 \cdot 94$ & $1 \cdot 01$ \\
\hline $35^{\circ}$ & $34 \cdot 48$ & $28 \cdot 87$ & 0.84 & $71 \cdot 77$ & $2 \cdot 08$ & $3 \cdot 78$ & 0.79 & $0 \cdot 21$ & $37 \cdot 84$ & $1 \cdot 10$ \\
\hline $40^{\circ}$ & $85 \cdot 57$ & $71 \cdot 10$ & 0.83 & 233.92 & 2.73 & $4 \cdot 60$ & $0 \cdot 82$ & $0 \cdot 18$ & $100 \cdot 19$ & $1 \cdot 17$ \\
\hline $45^{\circ}$ & $234 \cdot 21$ & $189 \cdot 60$ & $0 \cdot 81$ & $870 \cdot 00$ & $3 \cdot 71$ & $5 \cdot 38$ & $0 \cdot 84$ & $0 \cdot 16$ & $296 \cdot 19$ & $1 \cdot 26$ \\
\hline
\end{tabular}

Rectangular footing, $L / B=3$

\begin{tabular}{|c|c|c|c|c|c|c|c|c|c|c|}
\hline$\phi$ & $N_{\gamma}$ & $s_{\gamma} N_{\gamma}$ (LB) & $s_{\gamma}(\mathrm{LB})$ & $s_{\gamma} N_{\gamma}$ (UB) & $s_{\gamma}(\mathrm{UB})$ & $\Delta \mathrm{UB} / \Delta \mathrm{LB}$ & $w(\mathrm{LB})$ & $w(\mathrm{UB})$ & $s_{\gamma} N_{\gamma, \mathrm{w}}$ & $s_{\gamma, \mathrm{w}}$ \\
\hline $25^{\circ}$ & $6 \cdot 49$ & $5 \cdot 16$ & $0 \cdot 80$ & $11 \cdot 74$ & $1 \cdot 81$ & $4 \cdot 85$ & $0 \cdot 83$ & $0 \cdot 17$ & $6 \cdot 28$ & 0.97 \\
\hline $30^{\circ}$ & $14 \cdot 75$ & $12 \cdot 08$ & $0 \cdot 82$ & $26 \cdot 13$ & $1 \cdot 77$ & $3 \cdot 85$ & 0.79 & $0 \cdot 21$ & $14 \cdot 98$ & 1.02 \\
\hline $35^{\circ}$ & $34 \cdot 48$ & $28 \cdot 11$ & $0 \cdot 82$ & 68.69 & 1.99 & $3 \cdot 65$ & $0 \cdot 78$ & $0 \cdot 22$ & $36 \cdot 84$ & 1.07 \\
\hline $40^{\circ}$ & $85 \cdot 57$ & $67 \cdot 36$ & 0.79 & $214 \cdot 76$ & $2 \cdot 51$ & 4.45 & $0 \cdot 82$ & $0 \cdot 18$ & 94.41 & $1 \cdot 10$ \\
\hline $45^{\circ}$ & $234 \cdot 21$ & 174.90 & $0 \cdot 75$ & $786 \cdot 85$ & $3 \cdot 36$ & $5 \cdot 10$ & $0 \cdot 84$ & $0 \cdot 16$ & $275 \cdot 26$ & $1 \cdot 18$ \\
\hline
\end{tabular}

Rectangular footing, $L / B=4$

\begin{tabular}{|c|c|c|c|c|c|c|c|c|c|c|}
\hline$\phi$ & $N_{\gamma}$ & $s_{\gamma} N_{\gamma}$ (LB) & $s_{\gamma}(\mathrm{LB})$ & $s_{\gamma} N_{\gamma}$ (UB) & $s_{\gamma}(\mathrm{UB})$ & $\Delta \mathrm{UB} / \Delta \mathrm{LB}$ & $w(\mathrm{LB})$ & $w(\mathrm{UB})$ & $s_{\gamma} N_{\gamma, \mathrm{w}}$ & $s_{\gamma, \mathrm{w}}$ \\
\hline $25^{\circ}$ & $6 \cdot 49$ & $5 \cdot 15$ & 0.79 & $11 \cdot 30$ & 1.74 & 3.97 & $0 \cdot 80$ & $0 \cdot 20$ & $6 \cdot 39$ & 0.98 \\
\hline $30^{\circ}$ & 14.75 & 11.98 & $0 \cdot 81$ & $25 \cdot 20$ & 1.71 & $3 \cdot 40$ & 0.77 & 0.23 & 14.98 & 1.02 \\
\hline $35^{\circ}$ & 34.48 & $27 \cdot 50$ & $0 \cdot 80$ & $67 \cdot 50$ & 1.96 & 3.75 & 0.79 & $0 \cdot 21$ & $35 \cdot 92$ & 1.04 \\
\hline $40^{\circ}$ & 85.57 & 64.78 & 0.76 & $203 \cdot 40$ & $2 \cdot 38$ & $4 \cdot 17$ & $0 \cdot 81$ & $0 \cdot 19$ & 91.58 & 1.07 \\
\hline $45^{\circ}$ & $234 \cdot 21$ & $165 \cdot 00$ & $0 \cdot 70$ & $739 \cdot 00$ & $3 \cdot 16$ & $5 \cdot 19$ & $0 \cdot 84$ & $0 \cdot 16$ & $257 \cdot 66$ & $1 \cdot 10$ \\
\hline
\end{tabular}

level of the base of the footing, as opposed to simply a surcharge applied on the soil surface with a footing also resting on the soil surface, does have an impact on what happens below the footing base level. When that is ignored by making $d_{\gamma}=1$, the effects appear in the value of $d_{\mathrm{q}}$.

The depth factor $d_{\mathrm{q}}$ is plotted in Fig. 11 with respect to the depth of embedment for the five friction angles examined: $25^{\circ}, 30^{\circ}, 35^{\circ}, 40^{\circ}$ and $45^{\circ}$. The following equation fits well the numbers for $\phi=25^{\circ}$ to $45^{\circ}$ in the $D / B$ range from 0 to 2 .

$$
d_{\mathrm{q}}=1+(0 \cdot 0036 \phi+0 \cdot 393)\left(\frac{D}{B}\right)^{-0 \cdot 27}
$$

In this and all subsequent equations presented in the paper it is assumed that the angle of soil internal friction, $\phi$, is expressed in degrees. 


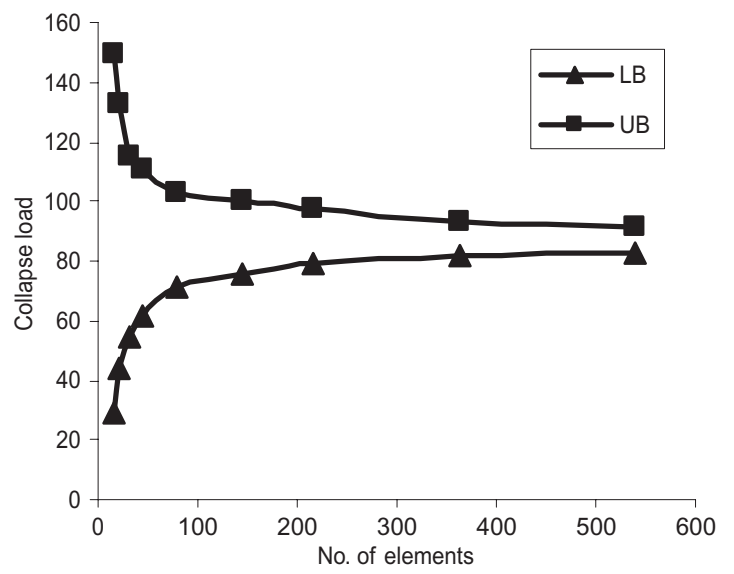

(a)

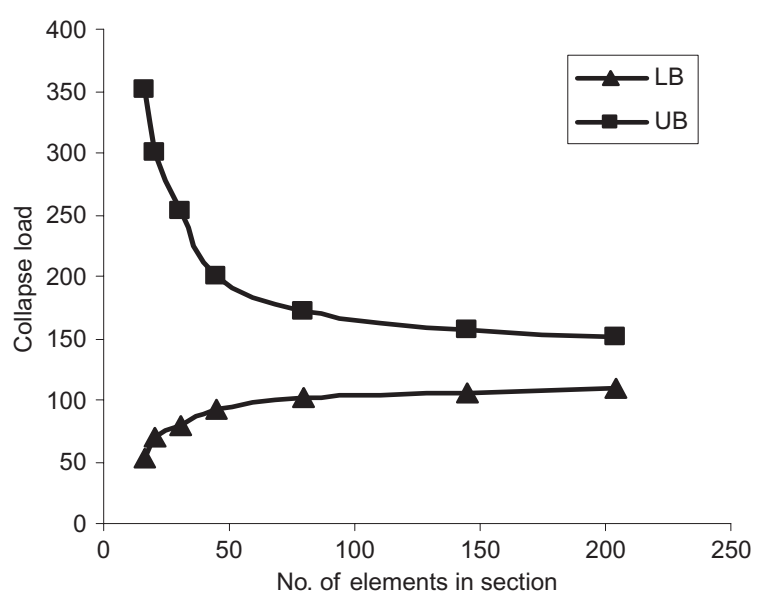

(b)

Fig. 12. Convergence for: (a) strip footings; (b) circular footings

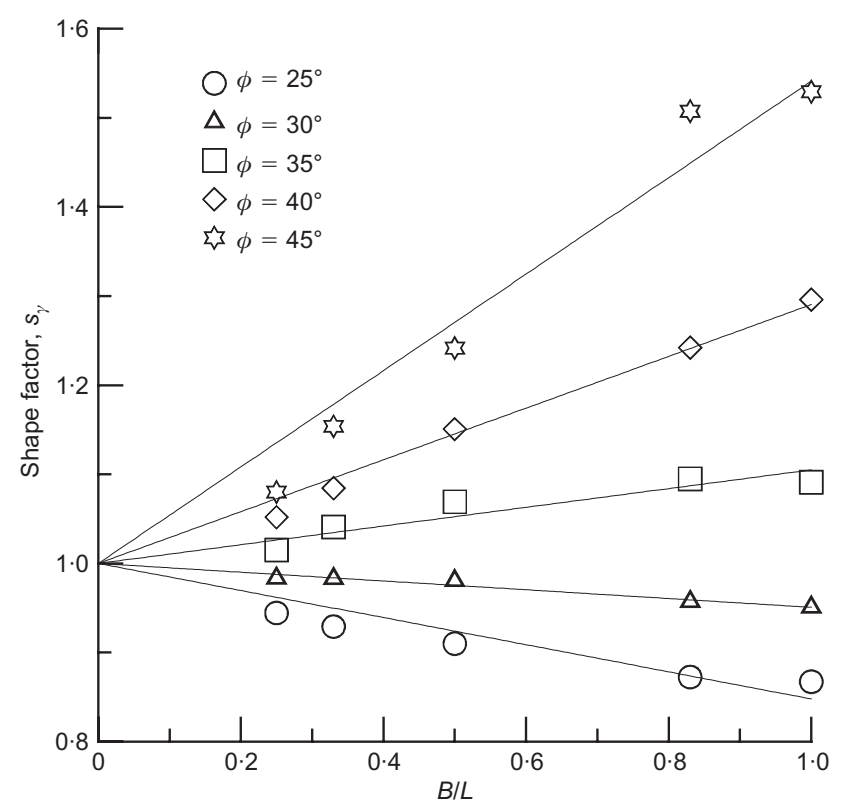

Fig. 13. Variation of shape factor $s_{\gamma}$ for surface footings with respect to $B / L$

\section{Determination of $\mathrm{s}_{\gamma}$}

For a square, circular or rectangular footing on the surface of a soil deposit, equation (1) becomes

$$
q_{\mathrm{bL}}=0.5 \gamma B s_{\gamma} N_{\gamma}
$$

Given that $0.5 \gamma B=1$ in our calculations, the calculated bounds on $q_{\mathrm{bL}}$ are bounds on $s_{\gamma} N_{\gamma}$. These values are shown in Table 6. The lower-bound $s_{\gamma}$ is obtained by dividing the lower-bound $s_{\gamma} N_{\gamma}$ by the corresponding $N_{\gamma}$ value from Martin (2005), shown in the second column of the table (and approximated by equation (7)). The bounds on $s_{\gamma}$ are also given in Table 6.

Taking the average of the upper and lower bounds as our best estimate of $s_{\gamma}$ would be appropriate if the lower and upper bounds converged to a common value at the same rate with increasing mesh refinement. It was observed, however, particularly for rectangular footings (for which computation accuracy drops significantly with increasing values of $L / B$ because of the coarser mesh that must be used), that the convergence rates are different for lower- and upper-bound calculations. A convergence study was performed for each of the 3D shapes considered for footings in the present paper by using progressively finer meshes. The convergence rates are approximately the same for lower- and upper-bound computations for the plane-strain case, as shown in Fig. 12(a), but the convergence rates for bounds on the bearing capacity of footings with finite values of $L$ are significantly different (see Fig. 12(b)). This means that taking the average of the two bounds does not give the best estimate of $s_{\gamma}$, which is obtained instead from the asymptotes computed for the lower- and upper-bound solutions. If, say $\mathrm{LB}_{1}$ and $\mathrm{LB}_{2}$ are two lower-bound estimates on some quantity obtained with two different $\mathrm{FE}$ meshes, and $\mathrm{UB}_{1}$ and $\mathrm{UB}_{2}$ are two upper-bound solutions from two meshes like the two lowerbound meshes, then the ratio of convergence rates of bounding solutions can be written as

$$
\alpha=\frac{\Delta \mathrm{UB}}{\Delta \mathrm{LB}}=\frac{\mathrm{UB}_{1}-\mathrm{UB}_{2}}{\mathrm{LB}_{2}-\mathrm{LB}_{1}}
$$

Given that information, the point of intersection of LB and UB plots (which we may call a weighted-average approximation to the collapse load) can be estimated as

$$
\mathrm{PI}=w_{\mathrm{LB}} \mathrm{LB}_{1}+w_{\mathrm{UB}} \mathrm{UB}_{1}
$$

where

$$
w_{\mathrm{LB}}=\frac{\alpha}{1+\alpha}, \quad w_{\mathrm{UB}}=\frac{1}{1+\alpha}
$$

To assess the level of accuracy that can be expected from this approach, $N_{\gamma}$ was calculated using the above formula and coarse meshes with the same pattern as the crosssections of the $3 \mathrm{D}$ meshes used for circular and rectangular footings. The results of this test are presented in the last two columns of Table 4. The coarse meshes used in the $N_{\gamma}$ computations result in a wide gap between bounds (as observed in some of the 3D calculations), but the weighted average estimates, $N_{\gamma, \mathrm{w}}$, are quite close to the exact values of $N_{\gamma}$.

Figure 13 shows the results of calculations for surface footings. These results suggest that there are no simple generalisations, based on physical rationalisations, as to what the shape factor $s_{\gamma}$ should be. It can be greater or less than 1 , and increase or decrease with increasing $B / L$. Note that $s_{\gamma}$ is both less than 1 and decreases with increasing $B / L$ for $\phi$ $=25^{\circ}$ and $\phi=30^{\circ}$, whereas it is greater than 1 and increases with increasing $B / L$ for $\phi=35^{\circ}-45^{\circ}$ (which are the cases of greater interest in practice). Note also that the value of $\phi$ that would lead to $s_{\gamma}=1$ for all values of $B / L$ is slightly greater than $30^{\circ}$. Using the Martin (2005) $N_{\gamma}$ values as a reference, our shape factors for $\phi=35^{\circ}-45^{\circ}$ are $15-$ $20 \%$ lower than the values of Erickson \& Drescher (2002), obtained using FLAC. A final interesting observation is that the variation of $s_{\gamma}$ with $B / L$ is essentially linear for all $\phi$ values considered. Zhu \& Michalowski (2005) also observed 
Table 7. Lower and upper bounds on $s_{\mathrm{q}}$ for square footing and their weighted averages

\begin{tabular}{|c|c|c|c|c|c|c|c|c|}
\hline$\phi$ & $D / B$ & $q_{\mathrm{bL}}(\mathrm{LB})$ & $q_{\mathrm{bL}}(\mathrm{UB})$ & $q_{\mathrm{bL}, \mathrm{w}}$ & $d_{\mathrm{q}} \gamma D N_{\mathrm{q}}$ & $s_{\mathrm{q}}(\mathrm{LB})$ & $s_{\mathrm{q}}(\mathrm{UB})$ & $s_{\mathrm{q}, \mathrm{w}}$ \\
\hline \multirow[t]{8}{*}{$25^{\circ}$} & $0 \cdot 0$ & $5 \cdot 10$ & $9 \cdot 05$ & $5 \cdot 87$ & $0 \cdot 00$ & & & \\
\hline & $0 \cdot 1$ & $10 \cdot 53$ & $14 \cdot 88$ & $11 \cdot 37$ & $4 \cdot 16$ & $1 \cdot 30$ & 1.40 & $1 \cdot 32$ \\
\hline & $0 \cdot 2$ & $15 \cdot 50$ & $21 \cdot 06$ & $16 \cdot 58$ & $7 \cdot 45$ & $1 \cdot 40$ & $1 \cdot 61$ & $1 \cdot 44$ \\
\hline & $0 \cdot 4$ & $25 \cdot 88$ & $34 \cdot 54$ & $27 \cdot 56$ & $13 \cdot 56$ & 1.53 & 1.88 & $1 \cdot 60$ \\
\hline & $0 \cdot 6$ & $37 \cdot 03$ & $49 \cdot 21$ & $39 \cdot 39$ & $19 \cdot 50$ & 1.64 & $2 \cdot 06$ & 1.72 \\
\hline & $0 \cdot 8$ & 48.94 & $65 \cdot 37$ & $52 \cdot 13$ & $25 \cdot 53$ & 1.72 & $2 \cdot 21$ & $1 \cdot 81$ \\
\hline & $1 \cdot 0$ & $61 \cdot 71$ & 82.94 & $65 \cdot 83$ & $31 \cdot 71$ & 1.79 & $2 \cdot 33$ & 1.89 \\
\hline & $2 \cdot 0$ & $138 \cdot 40$ & $198 \cdot 80$ & $150 \cdot 12$ & $64 \cdot 60$ & $2 \cdot 06$ & $2 \cdot 94$ & $2 \cdot 23$ \\
\hline \multirow[t]{8}{*}{$30^{\circ}$} & $0 \cdot 0$ & $12 \cdot 67$ & $21 \cdot 82$ & $14 \cdot 49$ & 0.00 & & & \\
\hline & $0 \cdot 1$ & $23 \cdot 58$ & $34 \cdot 50$ & $25 \cdot 75$ & $7 \cdot 31$ & 1.49 & 1.74 & 1.54 \\
\hline & $0 \cdot 2$ & $33 \cdot 44$ & $47 \cdot 44$ & $36 \cdot 22$ & $13 \cdot 01$ & 1.60 & 1.97 & 1.67 \\
\hline & 0.4 & $54 \cdot 04$ & $76 \cdot 94$ & $58 \cdot 59$ & $23 \cdot 57$ & 1.76 & $2 \cdot 34$ & 1.87 \\
\hline & 0.6 & $76 \cdot 22$ & $109 \cdot 35$ & $82 \cdot 80$ & 33.93 & 1.87 & $2 \cdot 58$ & $2 \cdot 01$ \\
\hline & $0 \cdot 8$ & $100 \cdot 10$ & $145 \cdot 60$ & $109 \cdot 14$ & $44 \cdot 38$ & 1.97 & $2 \cdot 79$ & $2 \cdot 13$ \\
\hline & $1 \cdot 0$ & $125 \cdot 60$ & $185 \cdot 41$ & 137.49 & 54.95 & $2 \cdot 06$ & $2 \cdot 98$ & $2 \cdot 24$ \\
\hline & $2 \cdot 0$ & $280 \cdot 60$ & $429 \cdot 60$ & $310 \cdot 21$ & $111 \cdot 65$ & $2 \cdot 40$ & $3 \cdot 65$ & $2 \cdot 65$ \\
\hline \multirow[t]{8}{*}{$35^{\circ}$} & $0 \cdot 0$ & $32 \cdot 96$ & $58 \cdot 60$ & $38 \cdot 61$ & $0 \cdot 00$ & & & \\
\hline & $0 \cdot 1$ & $55 \cdot 87$ & $85 \cdot 73$ & $62 \cdot 45$ & $13 \cdot 15$ & 1.74 & $2 \cdot 06$ & $1 \cdot 81$ \\
\hline & $0 \cdot 2$ & $76 \cdot 58$ & $117 \cdot 27$ & $85 \cdot 55$ & $23 \cdot 57$ & $1 \cdot 85$ & $2 \cdot 49$ & 1.99 \\
\hline & $0 \cdot 4$ & $119 \cdot 60$ & $188 \cdot 92$ & $134 \cdot 88$ & 42.98 & $2 \cdot 02$ & 3.03 & $2 \cdot 24$ \\
\hline & 0.6 & $165 \cdot 70$ & $265 \cdot 33$ & $187 \cdot 66$ & $61 \cdot 82$ & $2 \cdot 15$ & $3 \cdot 34$ & $2 \cdot 41$ \\
\hline & $0 \cdot 8$ & $215 \cdot 20$ & $347 \cdot 35$ & $244 \cdot 33$ & $80 \cdot 50$ & $2 \cdot 26$ & 3.59 & $2 \cdot 56$ \\
\hline & $1 \cdot 0$ & $268 \cdot 60$ & $432 \cdot 52$ & $304 \cdot 73$ & $99 \cdot 47$ & $2 \cdot 37$ & $3 \cdot 76$ & $2 \cdot 68$ \\
\hline & $2 \cdot 0$ & $594 \cdot 20$ & $959 \cdot 73$ & $674 \cdot 77$ & $201 \cdot 67$ & $2 \cdot 78$ & $4 \cdot 47$ & $3 \cdot 15$ \\
\hline \multirow[t]{8}{*}{$40^{\circ}$} & $0 \cdot 0$ & $91 \cdot 04$ & $184 \cdot 73$ & $112 \cdot 84$ & 0.00 & & & \\
\hline & $0 \cdot 1$ & $143 \cdot 30$ & $260 \cdot 76$ & $170 \cdot 64$ & $25 \cdot 86$ & $2 \cdot 02$ & $2 \cdot 94$ & $2 \cdot 23$ \\
\hline & $0 \cdot 2$ & $190 \cdot 50$ & $341 \cdot 83$ & $225 \cdot 72$ & $46 \cdot 75$ & $2 \cdot 13$ & $3 \cdot 36$ & $2 \cdot 41$ \\
\hline & $0 \cdot 4$ & $287 \cdot 00$ & $508 \cdot 50$ & $338 \cdot 55$ & $84 \cdot 74$ & $2 \cdot 31$ & $3 \cdot 82$ & $2 \cdot 66$ \\
\hline & $0 \cdot 6$ & $391 \cdot 10$ & $683 \cdot 55$ & $459 \cdot 16$ & $121 \cdot 41$ & $2 \cdot 47$ & $4 \cdot 11$ & $2 \cdot 85$ \\
\hline & $0 \cdot 8$ & $502 \cdot 80$ & $876 \cdot 80$ & $589 \cdot 84$ & $158 \cdot 20$ & $2 \cdot 60$ & $4 \cdot 37$ & $3 \cdot 02$ \\
\hline & $1 \cdot 0$ & $622 \cdot 10$ & $1086 \cdot 60$ & $730 \cdot 20$ & $195 \cdot 34$ & $2 \cdot 72$ & $4 \cdot 62$ & $3 \cdot 16$ \\
\hline & $2 \cdot 0$ & $1340 \cdot 00$ & $2385 \cdot 20$ & $1583 \cdot 24$ & $390 \cdot 71$ & $3 \cdot 20$ & $5 \cdot 63$ & $3 \cdot 76$ \\
\hline \multirow{8}{*}{$45^{\circ}$} & $0 \cdot 0$ & $277 \cdot 00$ & 683.09 & 364.79 & $0 \cdot 00$ & & & \\
\hline & $0 \cdot 1$ & $412 \cdot 40$ & $890 \cdot 12$ & $515 \cdot 67$ & $56 \cdot 18$ & $2 \cdot 41$ & $3 \cdot 68$ & $2 \cdot 69$ \\
\hline & $0 \cdot 2$ & $533 \cdot 80$ & $1111 \cdot 70$ & $658 \cdot 73$ & $101 \cdot 32$ & $2 \cdot 53$ & $4 \cdot 23$ & 2.90 \\
\hline & $0 \cdot 4$ & $777 \cdot 50$ & $1599 \cdot 56$ & $955 \cdot 21$ & $184 \cdot 35$ & $2 \cdot 71$ & 4.97 & $3 \cdot 20$ \\
\hline & $0 \cdot 6$ & $1029 \cdot 00$ & $2121 \cdot 28$ & $1265 \cdot 13$ & $264 \cdot 21$ & $2 \cdot 85$ & $5 \cdot 44$ & $3 \cdot 41$ \\
\hline & $0 \cdot 8$ & $1307 \cdot 00$ & $2667 \cdot 60$ & $1601 \cdot 13$ & $343 \cdot 16$ & $3 \cdot 00$ & $5 \cdot 78$ & $3 \cdot 60$ \\
\hline & $1 \cdot 0$ & $1601 \cdot 00$ & $3234 \cdot 50$ & $1954 \cdot 13$ & $421 \cdot 42$ & $3 \cdot 14$ & $6 \cdot 05$ & $3 \cdot 77$ \\
\hline & $2 \cdot 0$ & $3344 \cdot 00$ & $6577 \cdot 20$ & $4042 \cdot 95$ & $821 \cdot 58$ & $3 \cdot 73$ & $7 \cdot 17$ & $4 \cdot 48$ \\
\hline
\end{tabular}

a linear relationship between $s_{\gamma}$ and $B / L$ for values of $B / L$ less than approximately $0 \cdot 3$, but a more complex trend for $B / L>0 \cdot 3$. Their $s_{\gamma}$ values were also less than 1 for $\phi<$ $30^{\circ}$ and greater than 1 for $\phi>30^{\circ}$.

The following equation approximates quite well the shape factor for surface footings calculated using the present analysis:

$$
s_{\gamma}=1+(0 \cdot 0336 \phi-1) \frac{B}{L}
$$

In deriving equation (16), we used the bearing capacity of the square footing for $B / L=1$. The bearing capacity of the circular footing is slightly greater: the shape factor for a circular footing can be obtained by multiplying that of the square footing under the same conditions by $1+0.002 \phi$.

There are a number of physical processes whose interaction produces the bearing capacities of strip and finite-size footings. Two competing effects are the larger slip surface area for finite-size footings and the larger constraint/confinement imposed on the mechanism in the case of strip footings. The larger slip surface area (or larger plastic area) that would lead to $s_{\gamma}>1$ was observed for circular footings by Bolton \& Lau (1993) and by Zhu \& Michalowski (2005) using finite element analysis; it was earlier hypothesised by
Meyerhof (1963). In contrast, Vesic (1973) and Brinch Hansen (1970) proposed expressions yielding $s_{\gamma}<1$ (refer to Table 1).

Based on our results, it would appear that, for sufficiently low $\phi$ values, the greater constraint imposed on slip mechanisms in the case of the upper bound or greater confinement imposed on the stress field in the case of the lower-bound method more than compensates for the smaller slip surface area, resulting in $s_{\gamma}<1$. But for $\phi$ values greater than about $30^{\circ}$, which is the range we tend to see in practice, the larger slip surface area dominates, and $s_{\gamma}>1$. This contrasts with the Vesic (1973) and Brinch Hansen (1970) equations, popular in practice, which give $s_{\gamma}<1$ under all conditions. The physical reasoning that has been advanced in support of these equations is that square and rectangular footings generate smaller mean stress values below the footing, which in turn lead to lower shear strength than that available for a strip footing under conditions of plane strain. However, that argument applies only for footings placed on the surface of identical sand deposits, with the same relative density, for which $q_{\mathrm{bL}}$ will indeed be larger for a planestrain footing (for which $\phi$ will be higher) than for a circular or rectangular footing with the same width $B$. If equations in terms of $\phi$ are used in calculations, that 


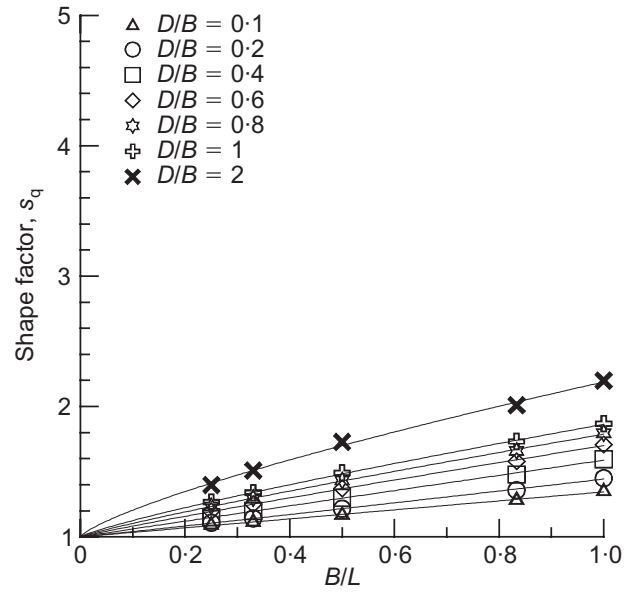

(a)

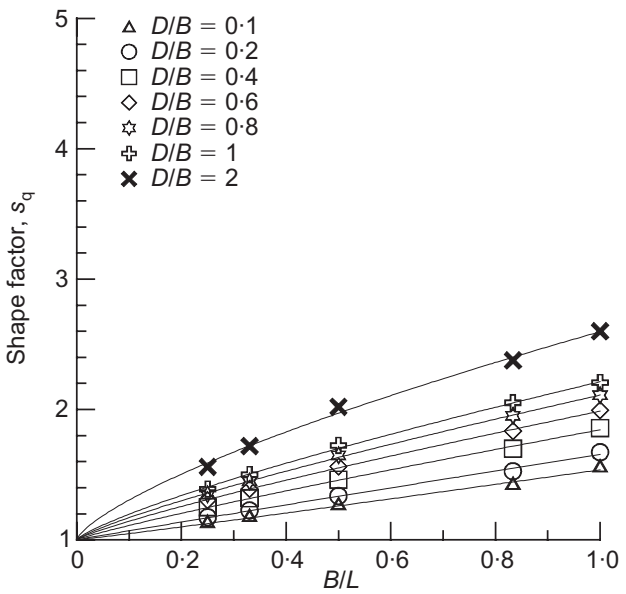

(b)

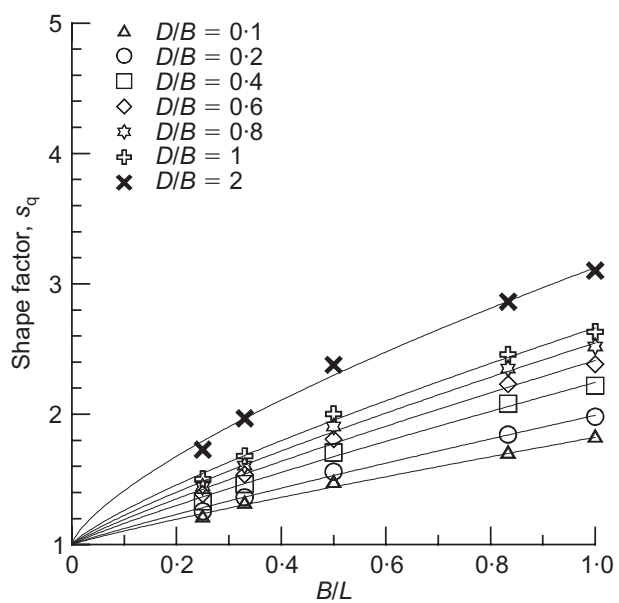

(c)

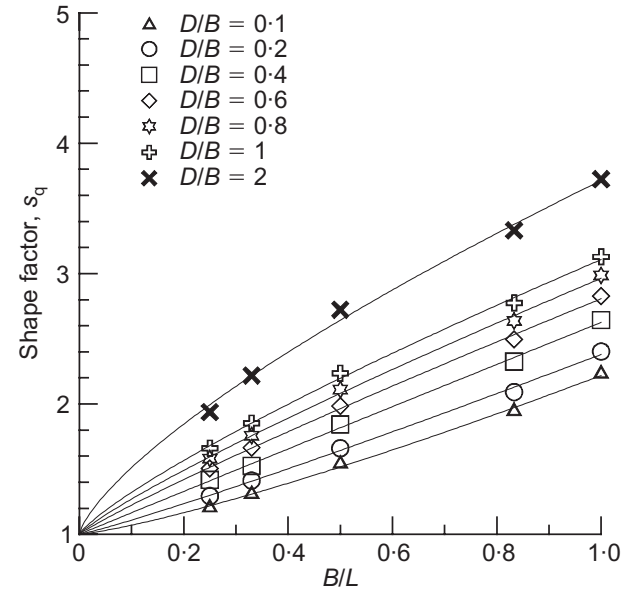

(d)

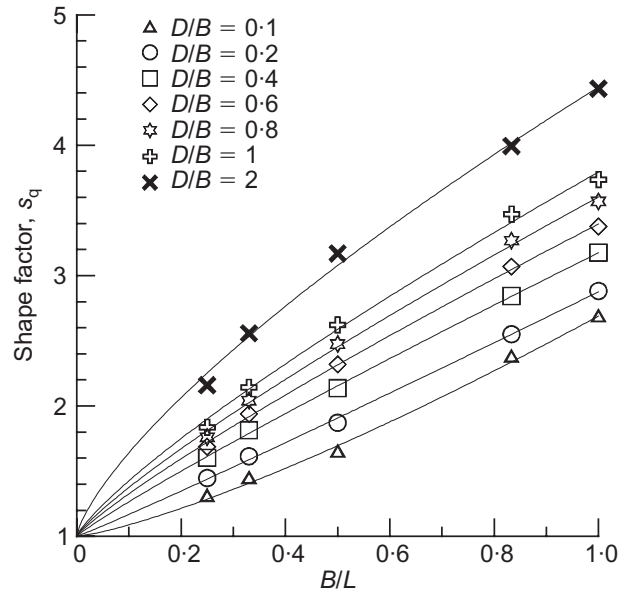

(e)

Fig. 14. Shape factor $s_{\mathrm{q}}$ against $B / L$ for various $D / B$ ranging from $0 \cdot 1$ to 2 and: (a) $\phi=25^{\circ}$; (b) $\phi=30^{\circ}$; (c) $\phi=35^{\circ}$; (d) $\phi=40^{\circ}$; (e) $\phi=45^{\circ}$

difference should not be accounted for by making $s_{\gamma}<1$, but rather by taking due account of the lower $\phi$ for footings in conditions other than plane-strain conditions. So a physical reasoning that does not comprehensively account for all the active processes may lead to the wrong conclusion, as in the case that has been made for $s_{\gamma}$ less than 1 for equations written in terms of $\phi$.
Determination of $\mathrm{s}_{q}$

The final factor to determine is the shape factor $s_{\mathrm{q}}$. Now equation (1) is used directly. We can rewrite it so that $s_{\mathrm{q}}$ is expressed as

$$
s_{\mathrm{q}}=\frac{q_{\mathrm{bL}}-0 \cdot 5\left(s_{\gamma} d_{\gamma}\right) \gamma B N_{\gamma}}{d_{\mathrm{q}} q_{0} N_{\mathrm{q}}}
$$




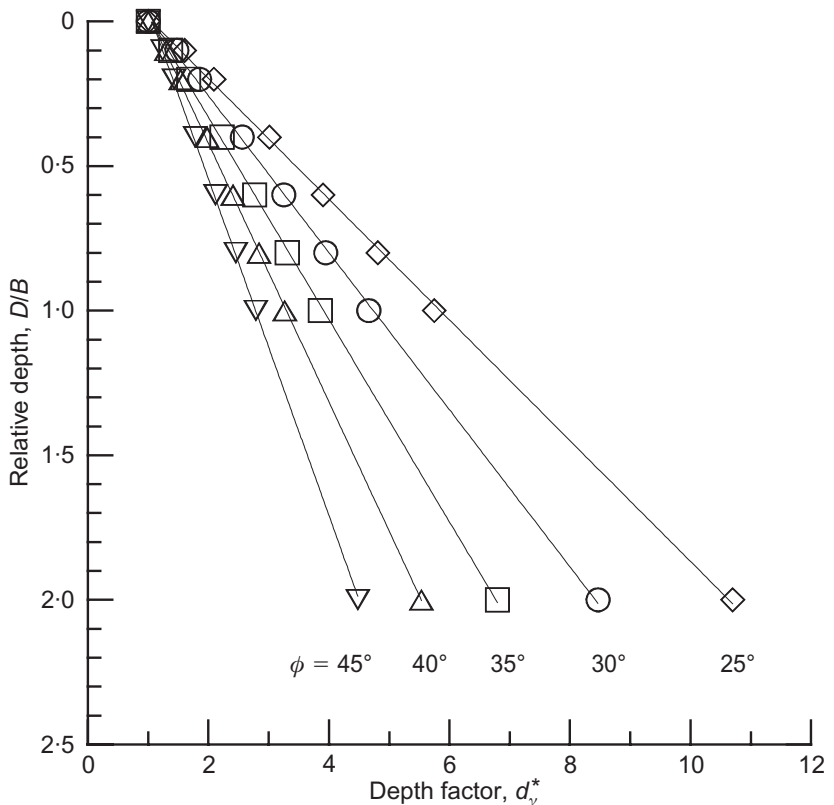

Fig. 15. Depth factor $d_{\gamma}^{*}$

It is clear that we must know $s_{\gamma}$ in order to calculate $s_{\mathrm{q}}$. Here we make the operational assumption that $s_{\gamma}$ is independent of depth. When we make this assumption, we implicitly decide that all of the depth-related effects that were not reflected in the values of $d_{\mathrm{q}}$, because they are coupled with the footing shape, will be captured by $s_{\mathrm{q}}$. Calculations are summarised for square footings in Table 7 . The results are shown graphically for all values of $L / B$ in Fig. 14. Note that $s_{\mathrm{q}}$ is not defined at $D=0$, when $q_{0}=0$, and that it must equal 1 for $B / L=0$ (plane strain). The mathematical form

$$
s_{\mathrm{q}}=1+f_{\mathrm{q} 1}\left(\phi, \frac{D}{B}\right)\left(\frac{B}{L}\right)^{f_{\mathrm{q} 2}\left(\phi, \frac{D}{B}\right)}
$$

can be used to fit the results, where functions $f_{\mathrm{q} 1}$ and $f_{\mathrm{q} 2}$ of $\phi$ and $D / B$ must be found such that the fit is optimal. For low $\phi$ values and $B / L \leqslant 0 \cdot 5$, the behaviour is very nearly linear, with $f_{\mathrm{q} 2}$ being approximately equal to 1 . The following expression fits the limit analysis results:

$$
s_{\mathrm{q}}=1+(0.098 \phi-1 \cdot 64)\left(\frac{D}{B}\right)^{0 \cdot 7-0 \cdot 01 \phi}\left(\frac{B}{L}\right)^{1-0 \cdot 16\left(\frac{D}{B}\right)}
$$

For small $D / B$ values, equation (19) is approximately linear in $B / L$. The equation, for $B / L=1$, may be applied to square footings. For circular footings, the $s_{\mathrm{q}}$ of equation (19) must be multiplied by an additional factor equal to $1+$ $0 \cdot 0025 \phi$.

\begin{tabular}{|c|c|c|c|c|c|c|c|c|c|c|c|}
\hline \multirow[t]{2}{*}{$\phi$} & \multirow[t]{2}{*}{$D / B$} & \multirow[t]{2}{*}{$q_{\mathrm{bL}}(2 \mathrm{D})$} & \multirow[t]{2}{*}{$d_{\gamma}^{*}$} & \multicolumn{2}{|c|}{ Circular } & \multicolumn{2}{|c|}{ Square } & \multicolumn{2}{|c|}{$L / B=2$} & \multicolumn{2}{|c|}{$L / B=3$} \\
\hline & & & & $q_{\mathrm{bL}}$ & $s_{\gamma}^{*}$ & $q_{\mathrm{bL}}$ & $s_{\gamma}^{*}$ & $q_{\mathrm{bL}}$ & $s_{\gamma}^{*}$ & $q_{\mathrm{bL}}$ & $s_{\gamma}^{*}$ \\
\hline \multirow[t]{7}{*}{$25^{\circ}$} & $0 \cdot 0$ & $6 \cdot 49$ & $1 \cdot 00$ & $6 \cdot 22$ & 0.96 & $5 \cdot 87$ & 0.90 & $6 \cdot 15$ & 0.95 & $6 \cdot 28$ & 0.97 \\
\hline & $0 \cdot 1$ & $10 \cdot 65$ & $1 \cdot 64$ & $12 \cdot 14$ & $1 \cdot 14$ & $11 \cdot 37$ & $1 \cdot 07$ & $10 \cdot 88$ & $1 \cdot 02$ & $10 \cdot 80$ & $1 \cdot 01$ \\
\hline & $0 \cdot 2$ & $13 \cdot 94$ & $2 \cdot 15$ & $17 \cdot 61$ & $1 \cdot 26$ & $16 \cdot 58$ & $1 \cdot 19$ & $15 \cdot 10$ & $1 \cdot 08$ & $14 \cdot 69$ & $1 \cdot 05$ \\
\hline & $0 \cdot 4$ & $20 \cdot 05$ & $3 \cdot 09$ & $29 \cdot 09$ & 1.45 & $27 \cdot 56$ & $1 \cdot 37$ & $23 \cdot 78$ & $1 \cdot 19$ & $22 \cdot 54$ & $1 \cdot 12$ \\
\hline & 0.6 & $25 \cdot 99$ & $4 \cdot 01$ & $41 \cdot 61$ & $1 \cdot 60$ & $39 \cdot 39$ & $1 \cdot 52$ & $33 \cdot 02$ & $1 \cdot 27$ & $30 \cdot 80$ & $1 \cdot 18$ \\
\hline & $0 \cdot 8$ & $32 \cdot 02$ & $4 \cdot 93$ & $55 \cdot 09$ & $1 \cdot 72$ & $52 \cdot 13$ & $1 \cdot 63$ & 43.03 & $1 \cdot 34$ & $39 \cdot 66$ & $1 \cdot 24$ \\
\hline & $1 \cdot 0$ & $38 \cdot 20$ & $5 \cdot 89$ & $69 \cdot 81$ & $1 \cdot 83$ & $65 \cdot 83$ & $1 \cdot 72$ & $54 \cdot 00$ & $1 \cdot 41$ & $49 \cdot 23$ & $1 \cdot 29$ \\
\hline \multirow[t]{7}{*}{$30^{\circ}$} & $0 \cdot 0$ & $14 \cdot 75$ & $1 \cdot 00$ & $15 \cdot 65$ & 1.06 & $14 \cdot 49$ & 0.98 & $14 \cdot 94$ & $1 \cdot 01$ & $14 \cdot 98$ & $1 \cdot 02$ \\
\hline & $0 \cdot 1$ & $22 \cdot 06$ & $1 \cdot 50$ & $27 \cdot 76$ & $1 \cdot 26$ & $25 \cdot 75$ & $1 \cdot 17$ & $24 \cdot 03$ & $1 \cdot 09$ & $23 \cdot 40$ & $1 \cdot 06$ \\
\hline & $0 \cdot 2$ & $27 \cdot 76$ & $1 \cdot 88$ & 38.99 & $1 \cdot 40$ & $36 \cdot 22$ & $1 \cdot 30$ & $32 \cdot 24$ & $1 \cdot 16$ & $30 \cdot 83$ & $1 \cdot 11$ \\
\hline & $0 \cdot 4$ & $38 \cdot 32$ & $2 \cdot 60$ & $62 \cdot 63$ & 1.63 & $58 \cdot 59$ & $1 \cdot 53$ & $49 \cdot 57$ & $1 \cdot 29$ & $46 \cdot 22$ & $1 \cdot 21$ \\
\hline & 0.6 & $48 \cdot 68$ & $3 \cdot 30$ & $88 \cdot 45$ & $1 \cdot 82$ & $82 \cdot 80$ & $1 \cdot 70$ & $68 \cdot 40$ & $1 \cdot 40$ & $62 \cdot 52$ & $1 \cdot 28$ \\
\hline & $0 \cdot 8$ & $59 \cdot 13$ & $4 \cdot 01$ & $116 \cdot 66$ & 1.97 & $109 \cdot 14$ & $1 \cdot 85$ & $88 \cdot 83$ & $1 \cdot 50$ & $79 \cdot 89$ & $1 \cdot 35$ \\
\hline & $1 \cdot 0$ & $69 \cdot 70$ & $4 \cdot 73$ & $147 \cdot 25$ & $2 \cdot 11$ & $137 \cdot 49$ & 1.97 & $111 \cdot 04$ & 1.59 & 98.59 & 1.41 \\
\hline \multirow[t]{7}{*}{$35^{\circ}$} & $0 \cdot 0$ & $34 \cdot 48$ & $1 \cdot 00$ & $41 \cdot 33$ & $1 \cdot 20$ & $38 \cdot 61$ & $1 \cdot 12$ & $37 \cdot 84$ & $1 \cdot 10$ & $36 \cdot 84$ & $1 \cdot 07$ \\
\hline & $0 \cdot 1$ & $47 \cdot 63$ & $1 \cdot 38$ & $68 \cdot 01$ & $1 \cdot 43$ & $62 \cdot 45$ & $1 \cdot 31$ & 56.97 & $1 \cdot 20$ & $54 \cdot 09$ & $1 \cdot 14$ \\
\hline & $0 \cdot 2$ & $58 \cdot 05$ & $1 \cdot 68$ & $92 \cdot 41$ & 1.59 & $85 \cdot 55$ & 1.47 & 74.63 & $1 \cdot 29$ & $69 \cdot 17$ & $1 \cdot 19$ \\
\hline & $0 \cdot 4$ & $77 \cdot 46$ & $2 \cdot 25$ & $143 \cdot 84$ & $1 \cdot 86$ & $134 \cdot 88$ & 1.74 & $111 \cdot 71$ & 1.44 & $100 \cdot 43$ & $1 \cdot 30$ \\
\hline & 0.6 & $96 \cdot 30$ & $2 \cdot 79$ & 199.69 & $2 \cdot 07$ & $187 \cdot 66$ & 1.95 & $150 \cdot 83$ & $1 \cdot 57$ & 132.99 & $1 \cdot 38$ \\
\hline & $0 \cdot 8$ & 114.98 & $3 \cdot 33$ & 258.67 & $2 \cdot 25$ & $244 \cdot 33$ & $2 \cdot 12$ & $193 \cdot 34$ & 1.68 & $168 \cdot 06$ & 1.46 \\
\hline & $1 \cdot 0$ & $133 \cdot 95$ & $3 \cdot 88$ & $323 \cdot 47$ & $2 \cdot 41$ & $304 \cdot 73$ & $2 \cdot 28$ & $239 \cdot 99$ & $1 \cdot 79$ & $206 \cdot 57$ & $1 \cdot 54$ \\
\hline \multirow[t]{7}{*}{$40^{\circ}$} & $0 \cdot 0$ & $85 \cdot 57$ & $1 \cdot 00$ & $121 \cdot 45$ & $1 \cdot 42$ & $112 \cdot 84$ & $1 \cdot 32$ & $100 \cdot 19$ & $1 \cdot 17$ & $94 \cdot 41$ & $1 \cdot 10$ \\
\hline & $0 \cdot 1$ & $111 \cdot 43$ & $1 \cdot 30$ & $184 \cdot 61$ & $1 \cdot 66$ & $170 \cdot 64$ & $1 \cdot 53$ & $141 \cdot 46$ & $1 \cdot 27$ & $129 \cdot 80$ & $1 \cdot 16$ \\
\hline & $0 \cdot 2$ & $132 \cdot 32$ & $1 \cdot 55$ & $242 \cdot 56$ & $1 \cdot 83$ & $225 \cdot 72$ & $1 \cdot 71$ & $179 \cdot 56$ & $1 \cdot 36$ & $162 \cdot 30$ & $1 \cdot 23$ \\
\hline & $0 \cdot 4$ & $170 \cdot 31$ & 1.99 & $361 \cdot 46$ & $2 \cdot 12$ & $338 \cdot 55$ & 1.99 & $258 \cdot 87$ & $1 \cdot 52$ & $226 \cdot 05$ & $1 \cdot 33$ \\
\hline & 0.6 & $206 \cdot 98$ & $2 \cdot 42$ & $490 \cdot 93$ & $2 \cdot 37$ & $459 \cdot 16$ & $2 \cdot 22$ & $344 \cdot 64$ & $1 \cdot 67$ & $299 \cdot 72$ & 1.45 \\
\hline & $0 \cdot 8$ & 243.77 & $2 \cdot 85$ & $628 \cdot 18$ & $2 \cdot 58$ & $589 \cdot 84$ & $2 \cdot 42$ & $438 \cdot 67$ & $1 \cdot 80$ & 376.67 & 1.55 \\
\hline & $1 \cdot 0$ & $280 \cdot 91$ & $3 \cdot 28$ & $779 \cdot 86$ & $2 \cdot 78$ & $730 \cdot 20$ & $2 \cdot 60$ & $542 \cdot 80$ & $1 \cdot 93$ & $461 \cdot 57$ & 1.64 \\
\hline \multirow[t]{7}{*}{$45^{\circ}$} & $0 \cdot 0$ & $234 \cdot 21$ & $1 \cdot 00$ & 398.80 & $1 \cdot 70$ & $364 \cdot 79$ & $1 \cdot 56$ & $296 \cdot 19$ & $1 \cdot 26$ & $275 \cdot 26$ & $1 \cdot 18$ \\
\hline & $0 \cdot 1$ & $290 \cdot 39$ & $1 \cdot 24$ & $568 \cdot 77$ & 1.96 & $515 \cdot 67$ & $1 \cdot 78$ & $399 \cdot 94$ & $1 \cdot 38$ & $364 \cdot 86$ & $1 \cdot 26$ \\
\hline & $0 \cdot 2$ & $335 \cdot 53$ & 1.43 & $724 \cdot 32$ & $2 \cdot 16$ & $658 \cdot 73$ & 1.96 & $498 \cdot 41$ & 1.49 & 448.61 & $1 \cdot 34$ \\
\hline & $0 \cdot 4$ & $418 \cdot 56$ & $1 \cdot 79$ & $1040 \cdot 75$ & $2 \cdot 49$ & $955 \cdot 21$ & $2 \cdot 28$ & $704 \cdot 88$ & $1 \cdot 68$ & $621 \cdot 22$ & 1.48 \\
\hline & $0 \cdot 6$ & $498 \cdot 42$ & $2 \cdot 13$ & $1379 \cdot 80$ & $2 \cdot 77$ & $1265 \cdot 13$ & $2 \cdot 54$ & $925 \cdot 73$ & $1 \cdot 86$ & $800 \cdot 91$ & $1 \cdot 61$ \\
\hline & $0 \cdot 8$ & $577 \cdot 37$ & $2 \cdot 47$ & $1729 \cdot 87$ & $3 \cdot 00$ & $1601 \cdot 13$ & $2 \cdot 77$ & $1164 \cdot 91$ & $2 \cdot 02$ & $991 \cdot 13$ & 1.72 \\
\hline & $1 \cdot 0$ & 655.63 & $2 \cdot 80$ & $2120 \cdot 67$ & $3 \cdot 23$ & $1954 \cdot 13$ & 2.98 & $1422 \cdot 37$ & $2 \cdot 17$ & $1195 \cdot 08$ & $1 \cdot 82$ \\
\hline
\end{tabular}

Table 8. Shape and depth factors, $s_{\gamma}^{*}$ and $d_{\gamma}^{*}$, for circular, square and rectangular footings 
Alternative form of bearing capacity equation for sands

As noted both in the present paper and in Salgado et al. (2004) for clays, shape and depth factors are interdependent, in contrast with the assumption that it is necessary to propose a bearing capacity equation of the form of equation (1). Whereas in the preceding subsections we retained the traditional form of the bearing capacity equation, and determined expressions for $s_{\mathrm{q}}, s_{\gamma}, d_{\mathrm{q}}$ and $d_{\gamma}$ that take due account of the interdependence of all quantities, we shall now explore an alternative form of the bearing equation that is simpler and does not attempt to dismember bearing capacity into artificial components.

A much simplified form of the bearing capacity equation can be proposed now that numerical limit analysis allows the overburden to be treated as a soil and not a surcharge. When we do that, the $N_{\mathrm{q}}$ term completely disappears, and we are left with

$$
q_{\mathrm{bL}}=\frac{1}{2} \gamma B s_{\gamma}^{*} d_{\gamma}^{*} N_{\gamma}
$$

As before, we follow tradition and separate depth and shape effects in equation (20) by using two factors $\left(d_{\gamma}^{*}\right.$ and $\left.s_{\gamma}^{*}\right)$. If we set $d_{\gamma}^{*}$ as a function of depth only, we can use equation (20) to calculate the bearing capacity of strip footings, for which $s_{\gamma}^{*}$ is 1 . For rectangular and circular footings, we find that $s_{\gamma}^{*}$ depends not only on $B / L$ but also on depth.

Using the same data as before, we can calculate $d_{\gamma}^{*}$ by using

$$
d_{\gamma}^{*}=\frac{q_{\mathrm{bL}, \text { strip }} \mid \frac{D}{B}}{q_{\mathrm{bL}, \text { strip }} \mid \frac{D}{B}=0}
$$

Figure 15 shows the depth factor, calculated as per equation (21), against $D / B$ for the five values of friction angle considered. The relationship between $d_{\gamma}^{*}$ and $D / B$ is almost perfectly linear. The following equation represents the straight lines shown in the figure quite well:

$$
d_{\gamma}^{*}=1+(8.404-0 \cdot 151 \phi) \frac{D}{B}
$$

where the friction angle is given in degrees.

The shape factor is calculated for a given $D / B$ value as

$$
s_{\gamma}^{*}=\frac{q_{\mathrm{bL}} \mid \frac{B}{L}}{q_{\mathrm{bL}, \text { strip }}}
$$

The value of $s_{\gamma}^{*}$ for $D / B=0$ is obviously the same as $s_{\gamma}$, given by equation (16). The ratio of $s_{\gamma}^{*}$ to $s_{\gamma}$ is therefore a function of $D / B$ and $B / L$ that takes the value of 1 at $D / B=$ 0 . The following equation captures this relationship quite well:

$$
\frac{s_{\gamma}^{*}}{s_{\gamma}}=1+\left(0.31+0.95 \frac{B}{L}\right)(2 \cdot 63+0.023 \phi)\left(\frac{D}{B}\right)^{1 \cdot 15-0 \cdot 54 \frac{B}{L}}
$$

In deriving the depth and shape factors, we assumed $d_{\gamma}^{*}$ to be independent of shape, with the result that the shape factor depends on depth, as clearly shown by equation (24). When we multiply together the shape factor and depth factor in equation (20), the issue of whether it is the depth factor that depends on $B / L$ or the shape factor that depends on $D / B$ disappears. In other words, the same final equation would have resulted had we assumed the shape factor to be independent of depth and the depth factor to depend on $B / L$, or, put more simply, had we assumed a single correction factor, function of $\phi, B / L$ and $D / B$.
All computed values of $d_{\gamma}^{*}$ and $s_{\gamma}^{*}$ for considered footing shapes and the ranges of $D / B$ and $\phi$ are prsented in Table 8.

\section{SUMMARY AND CONCLUSIONS}

Rigorous upper- and lower-bound analyses of circular, rectangular and strip footings in sand have been performed. The analyses provided ranges within which the exact collapse loads for the footings are to be found. This study became possible because of the development of efficient algorithms for optimisation of stress fields for lower-bound analysis and velocity fields for upper-bound analysis.

We have also examined the traditional bearing capacity equation and the underlying assumptions of superposition of surcharge and self-weight terms and independence of shape factors from depth and depth factors from shape of the footings. It was found that these assumptions are not valid. We proposed new shape and depth factors that do account for the interdependence of all the terms. Additionally, the derivation of these factors did not require making the assumption of superposition.

An alternative bearing capacity equation with a single term is simpler than the traditional form of the bearing capacity equation. For surface strip footings, the equation reduces to the traditional $\frac{1}{2} \gamma B N_{\gamma}$ form. Depth is accounted for by multiplying this term by a depth factor $d_{\gamma}^{*}$, and shape by multiplication by a shape factor $s_{\gamma}^{*}$. As shape and depth are not truly independent, the final equation can be viewed as simply the basic $\frac{1}{2} \gamma B N_{\gamma}$ term multiplied by factors that are functions of $B / L$ and $D / B$.

\section{REFERENCES}

Bolton, M. D. (1979). A guide to soil mechanics. London: Macmillan; reprinted by Chung Hwa Books, and published by M. D. and K. Bolton in 1998.

Bolton, M. D. \& Lau, C. K. (1993). Vertical bearing capacity factors for circular and strip footings on Mohr-Coulomb soil. Can. Geotech. J. 30, No. 6, 1024-1033.

Booker, J. R. (1969). Applications of theories of plasticity to cohesive frictional soils. PhD thesis, Sydney University.

Brinch Hansen, J. (1963). Cited once with different year in text.

Brinch Hansen, J. (1970). A revised and extended formula for bearing capacity, Bulletin No. 28. Lyngby: Danish Geotechnical Institute.

Caquot, A. \& Kerisel, J. (1953). Sur le terme de surface dans le calcul des fondations en milieu pulverent. Proc. $3^{\text {rd }}$ Int. Conf. Soil Mech. Found. Engng, Zurich 1, 336-337.

Davis, E. H. \& Booker, J. R. (1971). The bearing capacity of strip footings from the standpoint of plasticity theory. Proc. 1st Australian-New Zealand Conf. on Geomechanics, Melbourne, $275-282$

De Beer, E. E. (1970). Experimental determination of the shape factors and the bearing capacity factors of sand. Géotechnique 20, No. 4, 387-411.

Drucker, D. C., Greenberg, W. \& Prager, W. (1951). The safety factor of an elastic-plastic body in plane strain. Trans. ASME, J. Appl. Mech. 73, 371-378.

Drucker, D. C., Prager, W. \& Greenberg, H. J. (1952). Extended limit design theorems for continuous media. Q. Appl. Math. 9, No. 4, 381-389.

Erickson, H. L. \& Drescher, A. (2002). Bearing capacity of circular footings. J. Geotech. Geoenviron. Engng ASCE 128, No. 1, 38-43.

Hansen, B. \& Christiansen, N. H. (1969). Discussion of 'Theoretical bearing capacity of very shallow footings' by A. L. Larkin. J. Soil Mech. Found. Div. ASCE 95, No. SM6, 1568-1567.

Hill, R. (1951). On the state of stress in a plastic-rigid body at the yield point. Phil. Mag. 42, 868-875.

Krabbenhøft, K., Lyamin, A. V., Hijaj, M. \& Sloan, S W. (2005). A new discontinuous upper bound limit analysis formulation. Int. J. Numer. Methods Engng. 63, No. 7, 1069-1088.

Lyamin, A. V. (1999). Three-dimensional lower bound limit analysis 
using nonlinear programming. $\mathrm{PhD}$ thesis, Department of Civil, Surveying and Environmental Engineering, University of Newcastle, NSW, Australia.

Lyamin, A. V. \& Sloan, S. W. (2002a). Lower bound limit analysis using nonlinear programming. Int. J. Numer. Methods Engng 55, No. 5, 573-611.

Lyamin, A. V. \& Sloan, S. W. (2002b). Upper bound limit analysis using linear finite elements and nonlinear programming. Int. J. Numer. Anal. Methods Geomech. 26, No. 2, 181-216.

Lyamin, A. V., Krabbenhøft, K., Abbo, A. J. \& Sloan, S. W. (2005). General approach to modelling discontinuities in limit analysis. Proc. 11th Int. Conf. Int. Assoc. Computer Methods and Advances in Geomechanics (IACMAG 2005), Torino 1, 95-102.

Makrodimopoulos, A. \& Martin, C. M. (2005). Upper bound limit analysis using simplex strain elements and second-order cone programming, Technical Report 2288/2005. University of Oxford.

Martin, C. M. (2005). Exact bearing capacity calculations using the method of characteristics. Proc. 11th Int. Conf. IACMAG, Turin $4,441-450$.

Meyerhof, G. G. (1951). The ultimate bearing capacity of foundations. Géotechnique 2, No. 4, 301-332.
Meyerhof, G. G. (1963). Some recent research on bearing capacity of foundations. Can. Geotech. J. 1, No. 1, 16-26.

Pastor, J. (1978). Analyse limite: determination de solutions statiques completes. Application au talus vertical. Eur. J. Mech. A/Solids 2, No. 2, 176-196.

Reissner, H. (1924). Zum Erddruckproblem. Proc. 1st Int. Cong. Applied Mechanics, Delft, 295-311.

Salgado, R. (2008). The engineering of foundations. McGraw-Hill.

Salgado, R., Lyamin, A., Sloan, S. \& Yu, H. S. (2004). Two- and three-dimensional bearing capacity of footings in clay. Géotechnique 54, No. 5, 297-306.

Smith, C. C. (2005). Complete limiting stress solutions for the bearing capacity of strip footings on a Mohr-Coulomb soil. Géotechnique 55, No. 8, 607-612.

Terzaghi, K. (1943). Theoretical soil mechanics. New York: Wiley.

Vesic, A. S. (1973). Analysis of ultimate loads of shallow foundations. J. Soil Mech. Div. ASCE 99, No. SM1, 45-73.

Yu, H. S., Sloan, S. W., and Kleeman, P. W. (1994). A quadratic element for upper bound limit analysis. Engng Comput. 11, No. 3, 195-212.

Zhu, M. \& Michalowski, R. L. (2005). Shape factors for limit loads on square and rectangular footings. J. Geotech. Geoenviron. Engng 131, No. 2, 223-231. 